\title{
Prevention of intracellular calcium overload by blocking NCX
}

\author{
PhD Thesis
}

Judit Szepesi, Msc

Supervisor: Dr. András Tóth, PhD.

Department of Pharmacology \& Pharmacotherapy

Faculty of Medicine,

University of Szeged

Szeged, Hungary

Szeged

2015 


\section{PUBLICATION LISTS}

\section{a.)Publication list related to PhD topic}

I. Szepesi J, Acsai K, Sebok Z, Prorok J, Pollesello P, Levijoki J, Papp JG, Varro A, Toth A Comparison of the efficiency of $\mathrm{Na}+/ \mathrm{Ca} 2+$ exchanger or $\mathrm{Na}+\mathrm{H}+$ exchanger inhibition and their combination in reducing coronary reperfusion-induced arrhythmias JOURNAL OF PHYSIOLOGY AND PHARMACOLOGY 66:(2) pp. 215226. (2015) IF : 2.720

II. Nagy N, Kormos A, Kohajda Z, Szebeni A, Szepesi J, Pollesello P, Levijoki J, Acsai K, Virag L, Nanasi PP, Papp JGy, Varro A, Toth A

Selective $\mathrm{Na}+/ \mathrm{Ca} 2+$ exchanger inhibition prevents $\mathrm{Ca} 2+$ overload induced triggered arrhythmias.

BRITISH JOURNAL OF PHARMACOLOGY 171:pp.5665-5681(2014)

$I F .: 4,99$

\section{b.) Conference presentations related to $\mathrm{PhD}$ topic}

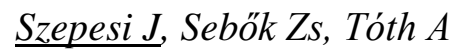

Effect of NCX and NHE inhibition on the development and duration of postischemic arrhythmias (NCX és NHEgátlás hatása posztiszkémiás aritmiák kialakulására és idötartamára) CARDIOLOGIA HUNGARICA 42:(Suppl.A) p. A37. (2012)

\section{$\underline{\text { Szepesi } J}$}

The effect of combined NCX1 and NHE1 blockade in acute ischemia/reperfusion injury in rat SEMINAR FOR YOUNG RESEARCHERS The physiology, pathophysiology and pharmacology of the cardiovascular system (2012)

\section{Posters}

\section{$\underline{\text { Szepesi } J}$}

The effect of NCX and NHE inhibition on the development and duration of post-ischemic arrhythmias

- Sudden Cardiac Death \& Cardioprotection conference and advanced workshop (2012)

- EHRA EUROPACE 2013 -The meeting of the european heart rhythm association (2013) 


\section{ABREVATIONS AND ACRONYSM}

$\left[\mathrm{Ca}^{2+}\right]_{\mathrm{i}}$ : intracellular calcium

AMI: acute myocardial infarction

AP: action potential

APD: action potential duration

ATX-II: anemone toxin

CF: coronary flow

DAD: delay after depolarization

DMSO: dimethyl sulphoxide

EAD: early after depolarization

ES: extrasystole

HR: heart rate

IR injury: ischaemia/ reperfusion injury

KH: Krebs-Henseleit solution

LVEDP: left ventricular end-diastolic pressure

LVP: left ventricular pressure

NCX: $\mathrm{Na}^{+}-\mathrm{Ca}^{2+}$ exchanger

NHE: $\mathrm{Na}^{+}-\mathrm{H}^{+}$exchanger

NKA: $\mathrm{Na}^{+} / \mathrm{K}^{+}$ATPase

ORM-10103: 5-nitro-2-(2-phenylchroman-6-yloxy)pyridine

PLN: phospholamban

PMCA: plasma membrane Ca-ATPase

revNCX: reverse NCX

SEA0400: 2-(4-((2,5-difluorophenyl)methoxy)phenoxy)-5-ethoxy-aniline

SERCA2a: sarcoplasmatic reticulum Ca ATPase

VF: ventricular fibrillation

VT: ventricular tachycardia 


\section{TABLE OF CONTENTS}

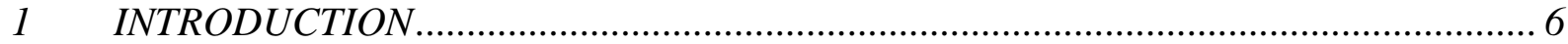

1.1 Intracellular $\mathrm{Ca}^{2+}$ homeostasis and excitation-contraction coupling....................... 8

1.2 Cardiac NCX structure and function ................................................................... 9

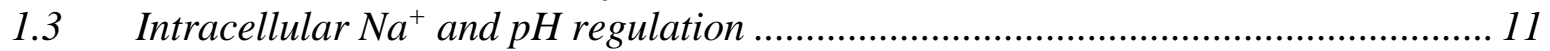

1.3.1 Intracellular $p H$ Regulation in the Cardiac Cell ............................................ 11

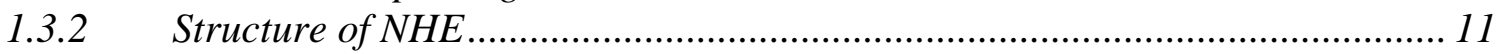

1.4 Effect of Ischaemia on Cellular Sodium and Calcium Homeostasis........................ 12

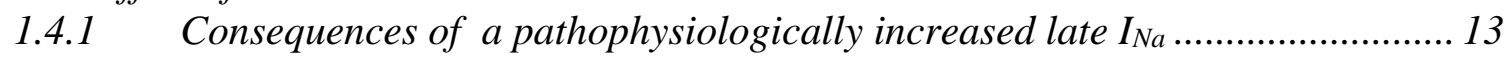

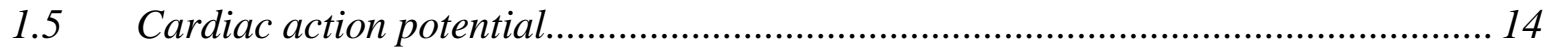

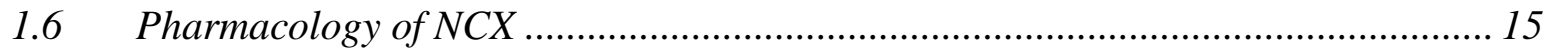

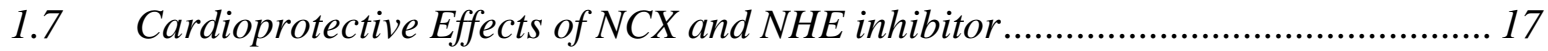

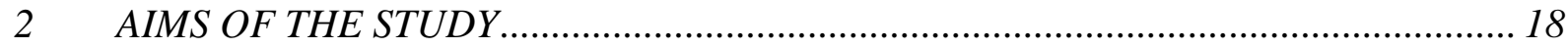

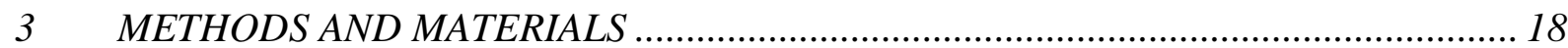

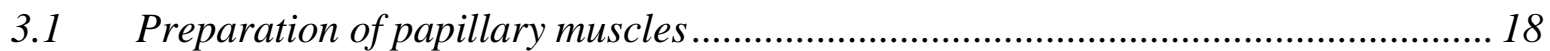

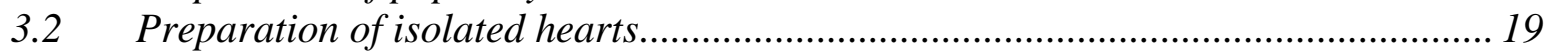

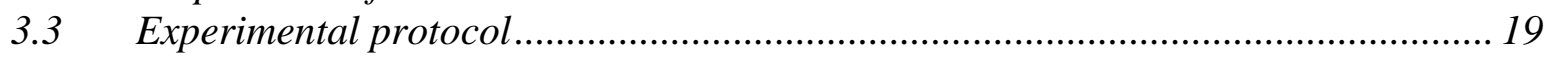

3.3.1 Recording of action potentials in multicellular preparations .......................... 19

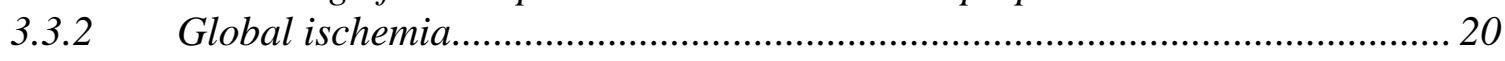

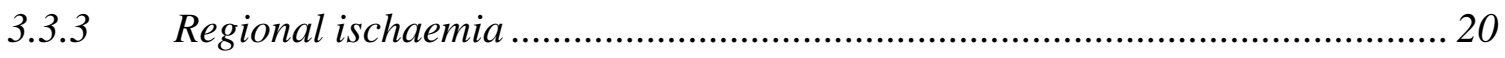

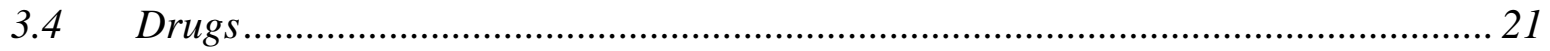

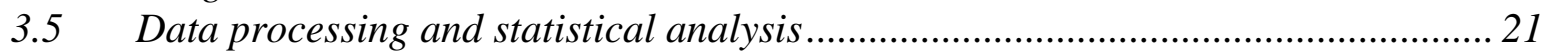

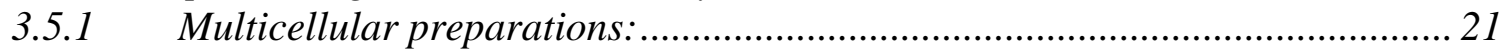

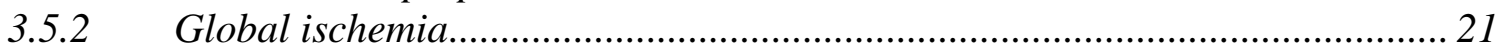

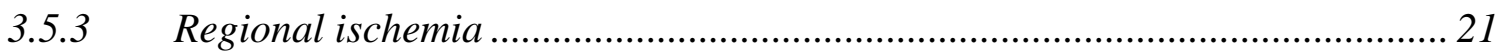

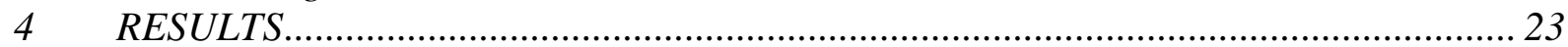

4.1 SEAO4OO and ORM-10103 fail to eliminate the APD lengthening effect of ATX-II 23

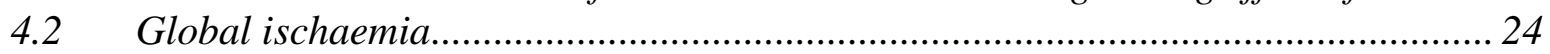

4.2.1 Comparison of the ischaemia-induced contracture's parameters .................... 24

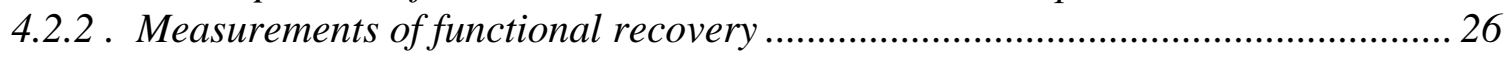

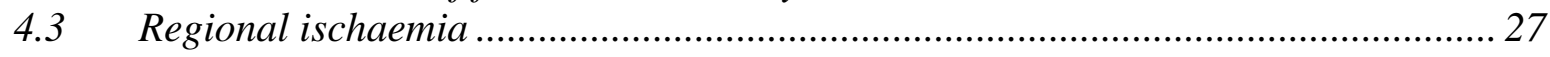

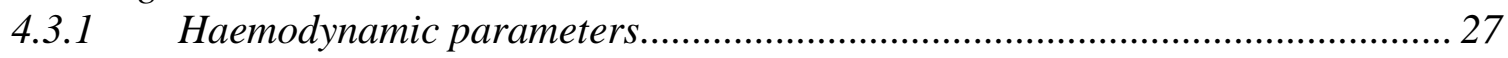

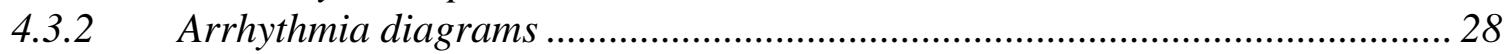

4.3.3 Quantitative analysis of the incidence and duration during reperfusion of the sinus rhythm (SR) and the three major types of arrhythmia (ES, VT and VF)................ 30

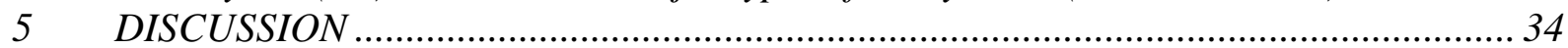

5.1 Failure of selective NCX inhibition to modulate ventricular AP .............................. 34

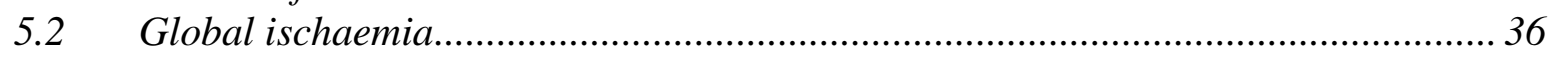

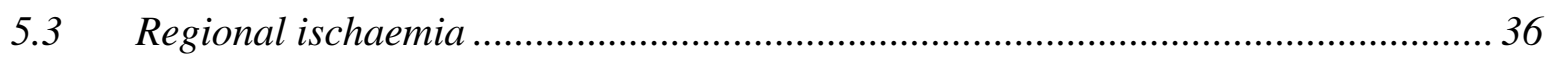

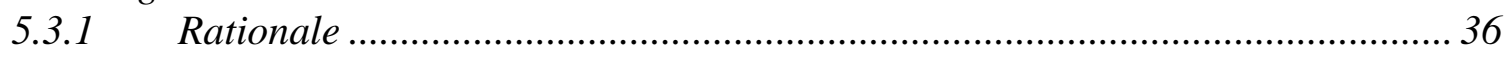

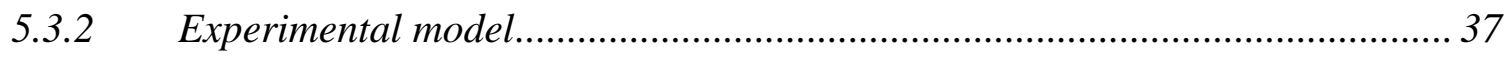

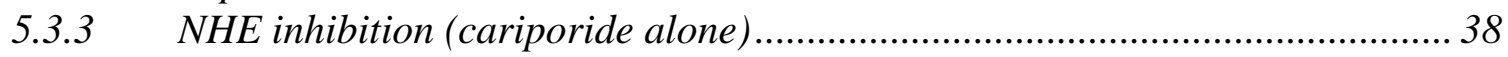

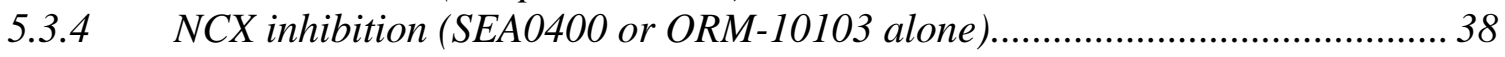

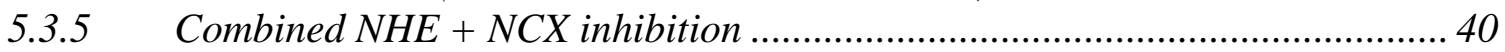

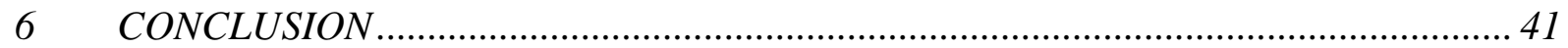

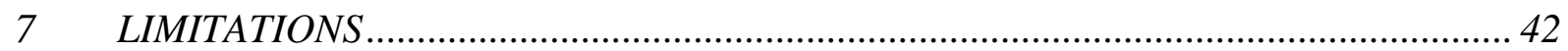

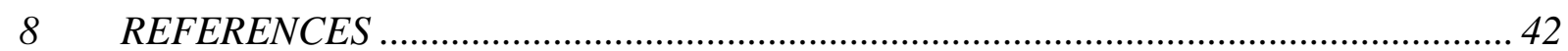

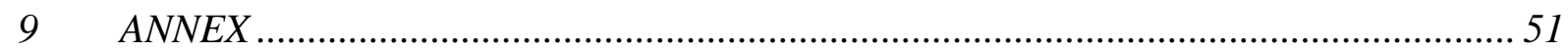

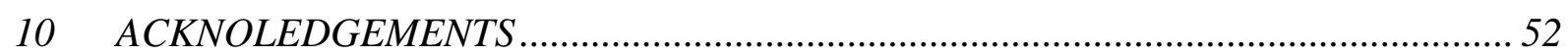




\section{SUMMARY}

Sodium-calcium exchange (NCX) is the major calcium $(\mathrm{Ca})$ efflux mechanism of ventricular cardiomyocytes. Pathological conditions linked to imbalances in oxygen supply and demand (for example, ischaemia, hypoxia and heart failure) are associated with disruptions in intracellular sodium $\left(\left[\mathrm{Na}^{+}\right]_{\mathrm{i}}\right)$ and calcium $\left(\left[\mathrm{Ca}^{2+}\right]_{\mathrm{i}}\right)$ concentration homeostasis of myocardial cells. Calcium overload of myocardial cells is associated with electrical instability, increased diastolic and reduced systolic force generation, and an increase in oxygen consumption. Nevertheless, both the sodium-hydrogen exchanger (NHE) and abnormal sodium channel conductance (that is, increased late sodium current $\left(\mathrm{I}_{\mathrm{NaL}}\right)$ ) are likely to contribute to the rise in $\left[\mathrm{Na}^{+}\right]_{i}$. The primary aim of the present project was to investigate in detail the effects of $\left[\mathrm{Ca}^{2+}\right]_{i}$ overload, induced either by increased late $\mathrm{Na}^{+}$current or by acute ischaemia/reperfusion in isolated canine multicellular preparations and in Langendorff-perfused hearts. The NHE and NCX were inhibited by cariporide and SEA0400 or the novel, more selective ORM-10103, respectively. SEA0400 and ORM-10103 fail to eliminate the APD lengthening effect of ATX-II independently of the sequence of application in canine preparations. NHE inhibition by cariporide was highly efficient in reducing the recorded reperfusion-induced arrhythmias. Following the application of SEA0400 or ORM10103 , the number and duration of arrhythmic periods were efficiently or moderately decreased. Surprisingly, the simultaneous inhibition of the NCX and NHE failed to significantly improve the antiarrhythmic efficacy reached by NCX blockade alone. Our present data support the hypothesis that selective, partial NCX inhibition may be antiarrhythmic via restricting the $\mathrm{Na}^{+}$-induced $\left[\mathrm{Ca}^{2+}\right]_{\mathrm{i}}$ elevation, and this protective effect is mediated primarily by its inhibitory effect on rev $\mathrm{I}_{\mathrm{NCX}}$. Therefore, NCX inhibition can be considered as a promising therapeutic strategy against $\mathrm{Ca}^{2+}$ overload-induced, revNCX-mediated cardiac arrhythmias. 


\section{INTRODUCTION}

Cardiovascular diseases are the leading causes of death all over the world. Heart diseases with ischaemic origin alone account for $>12 \%$ of all deaths; more than HIV/AIDS, tuberculosis, lung and breast cancer together. Heart failure (HF) and arrhythmias are the most serious conditions likely resulting in death. The causes of HF include of ischaemic coronary disease, myocardial infarction, chronic hypertension and valvular diseases. Coronary reperfusion therapy is a widely used intervention for the management of acute myocardial infarction (AMI). However, restoration of blood flow to previously ischaemic myocardium results in the so-called ischaemia/reperfusion (IR)-injury, which can be manifested as myocardial necrosis, arrhythmia, myocardial stunning and endothelial- and microvascular dysfunction including the no-reflow phenomenon. The mechanisms of the ischaemia/reperfusion injury consists of several pathways. Recently, there's increasing evidence for an important role in IR-injury on hypercontracture induced by calcium overload or low ATP level. Reperfusion of the heart after ischaemia may lead to lethal arrythmias [1]. In humans, the most common reperfusion arrhythmia is an accelerated idioventricular rhythm [2]. However, ventricular tachycardia and ventricular fibrillation remain the most important causes of sudden death following spontaneous restoration of the coronary flow. The development of cardiac arrhythmias require concomitant existence of a trigger (i.e.: extrasystoles, generated by large enough membrane potential oscillations, usually induced by perturbations in $\left[\mathrm{Ca}^{2+}\right]_{\mathrm{i}}$ handling, leading to $\left[\mathrm{Ca}^{2+}\right]_{\mathrm{i}}$ overload) and a substrate (i.e: large enough APD dispersion between adjacent cells, typically caused by an uneven reduction in the efficacy of AP repolarization) [3]. In normal conditions $\left[\mathrm{Ca}^{2+}\right]_{\mathrm{i}}$ is under a tight control due to a delicate balance between $\mathrm{Ca}^{2+}$ fluxes [4]. Therefore, $\left[\mathrm{Ca}^{2+}\right]_{\mathrm{i}}$ overload is prevented and triggered events cannot occur. Furthermore, the fast propagation of the action potencial and the homogenous repolarization (i.e.: small APD dispersion between adjacent cells) precedes circular reentry [3].

Crucial role of the severe disturbances in the intracellular ionic homeostasis (including changes in $\left.\left[\mathrm{Na}^{+}\right]_{i},\left[\mathrm{~K}^{+}\right]_{i},\left[\mathrm{H}^{+}\right]_{i},\left[\mathrm{Ca}^{2+}\right]_{i}\right)$ in the initiation and progression of potentially lethal cardiac arrhythmias has been demonstrated in a plethora of studies [5]. Prognosis of these arrhythmias are poor with a high rate of mortality, due to their complex and not fully understood pathomechanisms and the consequent sub-optimal medical treatment [6]. Since increased NCX activity is considered as a major cause of both the ischaemia induced tissue injury and 
postischaemic reperfusion arrhythmias, a beneficial effect of NCX inhibition against these pathological states seems highly feasible and is suggested by experts in the field.

The proposed cardioprotective, antiarrhythmic effects of selective, partial inhibition of NCX have been investigated in three studies utilizing several modells of ischaemia/reperfusion injury. One of these studies was carried out in canine cardiomyocytes on multicellular preparations (papillary muscles). In the other studies Langendorff-perfused rat hearts were used. The most recent NCX inhibitors, the fairly selective SEA0400 and the novel and more selective ORM-10103 were tested for antiischaemic, antiarrhythmic efficacy.

1) In the first study, ATX-II, an activator of the late sodium current, has been used to induce a majr rise in $\left[\mathrm{Na}^{+}\right]_{\mathrm{i}}$ (and subsequently leading to $\left[\mathrm{Ca}^{2+}\right]_{\mathrm{i}}$ overload) characteristic for a genetic disease (LQT3 syndrome) and also for acute ischemia-reperfusion. ATX-II is known to increase APD leading to both early afterdepolarizations (EADs) and ventricular tachycardia. Two principal questions were investigated: The effect of selective $I_{\mathrm{NCX}}$ inhibition on the arrhythmogenic $\left[\mathrm{Na}^{+}\right]_{\mathrm{i}}$ rise induced alterations of the variables of the $\left[\mathrm{Ca}^{2+}\right]_{i}$ homeostasis. The effect of selective $\mathrm{I}_{\mathrm{NCX}}$ inhibition on the arrhythmogenic $\left[\mathrm{Na}^{+}\right]_{i}$ rise induced alterations of the AP morphology (and APD) and AP dispersion.

This study has been carried out by a few investigators - my challenge was to analyze in canine multicellular preparations the effect of ORM-10103 on ATX-II induced APD prolongation. To characterize these effects two principal experimental arrangements were applied. (1) If the $\mathrm{I}_{\mathrm{Na}}$ activator was applied prior to the $\mathrm{I}_{\mathrm{NCX}}$ blockade, the question was whether selective NCX inhibition is suitable to revert the $\mathrm{I}_{\mathrm{NaL}}$ or $\mathrm{Na}^{+} / \mathrm{K}^{+}$pump induced APD prolongation or $\left[\mathrm{Ca}^{2+}\right]_{\mathrm{i}}$ rise. When the NCX inhibitor was applied first, the question was whether the inhibition is able to prevent the arrhythmogenic effects of $\mathrm{I}_{\mathrm{NaL}}$ activation.

2) In the second study an often used regional ischaemia/reperfusion model has been utilized in Langendorff-perfused rat hearts. Regional ischemia/reperfusion was introduced by ligating the left anterior descending coronary artery (LAD). The primary goal of this study was to evaluate and compare the putative protective efficacy of individual or combined inhibition of NHE and/or NCX against post-ischaemic arrhythmias.

3) In the third study the effects of NCX and/or NHE inhibition on the degree and kinetics of recovery of cardiac contractility during reperfusion following global ischaemia has been investigated, also in Langendorff-perfused rat hearts. In order to complete this study further experimental work is needed. 


\subsection{Intracellular $\mathrm{Ca}^{2+}$ homeostasis and excitation-contraction coupling}

$\mathrm{Ca}^{2+}$ is a very important intracellular messenger. Is is universal in the living organisms and nature has evolved multiple mechanisms to control the intracellular $\mathrm{Ca}^{2+}$ level. Calcium signaling is essential for many physiological processes, including muscle contraction, cell mobility, fertilization, exocytosis, and apoptosis. One of the major players in regulating intracellular $\mathrm{Ca}^{2+}$ is the $\mathrm{Na}^{+} / \mathrm{Ca}^{2+}$ exchanger (NCX). In cardiac excitation -contraction (E-C) coupling, a small amount of $\mathrm{Ca}^{2+}$ first enters through the L-type $\mathrm{Ca}^{2+}$ channel (LTCC) during membrane depolarization. This $\mathrm{Ca}^{2+}$ influx triggers a larger $\mathrm{Ca}^{2+}$ release through the $\mathrm{Ca}^{2+}$ release channels of the sarcoplasmic reticulum (SR), referred to as ryanodine receptors (RyRs). The gain of excitationcontraction (EC) expresses the relationship between SR Ca release flux and the Ca current that triggers it and is an expression of its efficiency. The released $\mathrm{Ca}^{2+}$ then binds to troponin $\mathrm{C}$ present within the myofilaments, which induces activation of the myofilaments and consequently muscle contraction [7].

Ca removal from the cytoplasm initiates the myocyte relaxation. There are two major routes of removal: SR Ca ATPase (SERCA2a) pumps $\mathrm{Ca}$ back into the SR and is regulated by phospholamban (PLN); the other is a subsequently transsarcolemmal $\mathrm{Ca}^{2+}$ removal through NCX, which operates in its forward mode when $\mathrm{Ca}^{2+}$ is high. NCX is a bi-directional transporter working in either forward and reverse mode depending on the electrochemical gradients of the substrate ions. Under physiological conditions, forward NCX removes majority of Ca that entered the cell through LCCs and reverse NCX, in order to maintain cellular Ca balance. The forward mode that removes calcium is coupled with sodium influx in $3 \mathrm{Na}^{+}-1 \mathrm{Ca}^{2+}$ stoichiometric ratio. Under physioloogical conditions and especially in pathological conditions such as ischaemia/reperfusion the NCX allows $\mathrm{Ca}^{2+}$ entry and sodium extrusion, called reverse mode operation. The plasma membrane Ca-ATPase (PMCA) and mitochondria are considered minor players in the balance of cellular $\mathrm{Ca}$ although their contribution should not be dismissed as there is accumulating evidence that they can influence cellular Ca stores and modify EC coupling [8]. A persistent reduction in cellular $\mathrm{Ca}$ efflux not matched by a decrease in $\mathrm{Ca}$ influx will result in increased cellular $\mathrm{Ca}$. The expectation is that this increased cellular Ca will accumulate in the SR rather than the cytoplasm if SERCA is performing normally. The increased SR store typically results in larger $\mathrm{Ca}$ transients and therefore increased contractility [9]. Conversely, an increase in Ca efflux will deplete SR stores and depress contractility. Among different species, the tendency to deplete or load SR $\mathrm{Ca}$ in resting cells appears to depend upon intracellular sodium concentration: in species with higher Na concentrations (e.g. mice/rats), SR loading appears to occur at rest whereas those with lower $\mathrm{Na}$ concentrations (e.g. rabbits/ guinea pigs/humans) are associated with SR Ca depletion at rest. These changes in SR Ca load in response to the levels of 
intracellular Na are mediated by NCX. Higher intracellular Na concentration increases the reverse NCX mediated $\mathrm{Ca}$ efflux and reduces forward NCX mediated Ca efflux, allowing SERCA to compete more effectively for $\mathrm{Ca}$ during the relaxation phase of the $\mathrm{Ca}$ transient. The general concept of SR loading and unloading in response to intracellular Na concentration has important implications for treatment of contractile dysfunction in heart failure [10, 11].

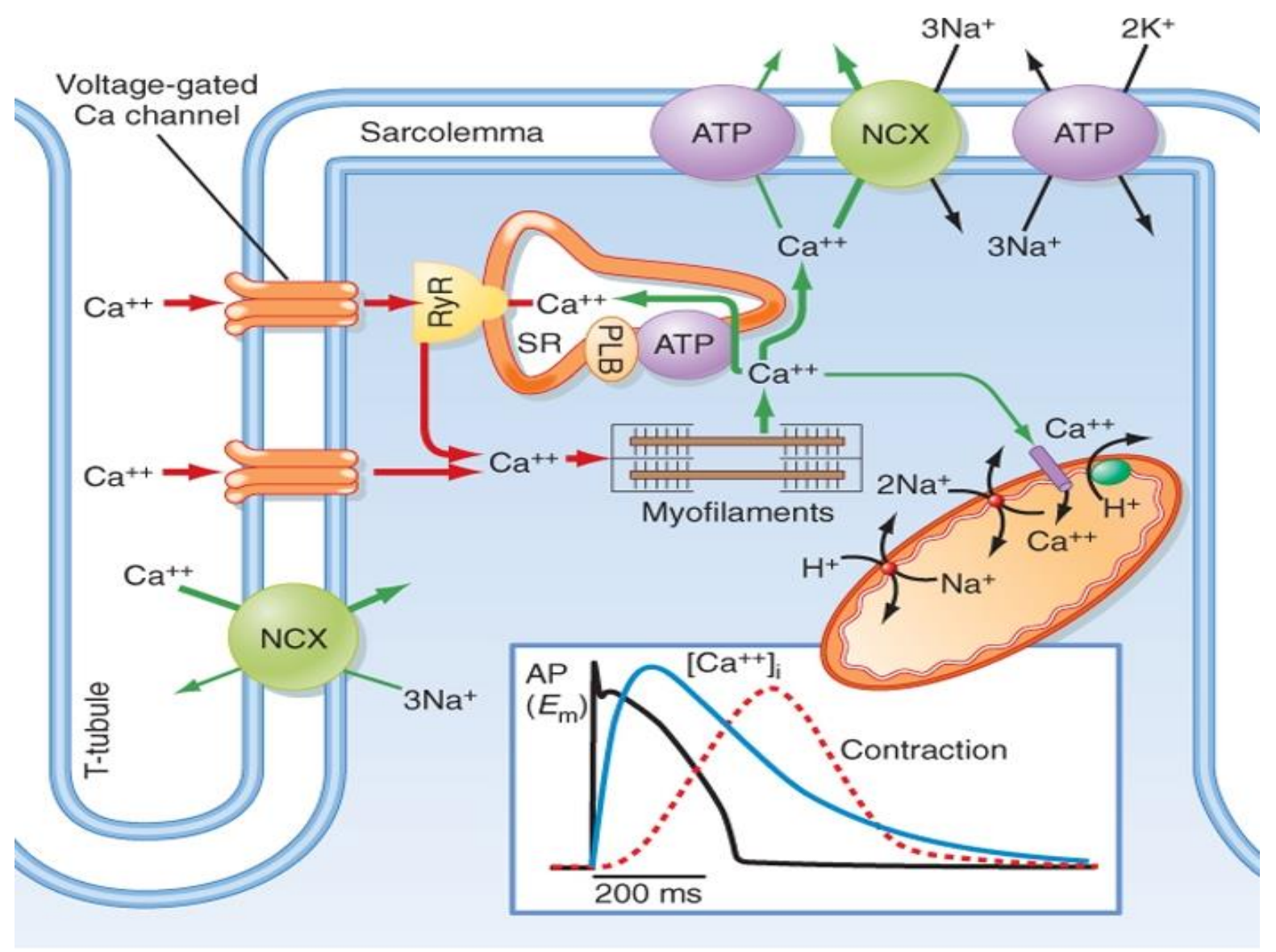

Fig.1: Electrical excitation at the sarcolemmal membrane activates voltage-gated $\mathrm{Ca}^{2+}$ channels, and the resulting $\mathrm{Ca}^{2+}$ entry activates $\mathrm{Ca}^{2+}$ release from the sarcoplasmic reticulum (SR) via ryanodine receptors (RyRs), resulting in contractile element activation. NCX, $\mathrm{Na}^{+} / \mathrm{Ca}^{2+}$ exchange; ATP, ATPase; PLB, phospholamban; SR, sarcoplasmic reticulum. Inset shows the time course of an action potential, $\mathrm{Ca}^{2+}$ transient and contraction. (Bers 2002).

\subsection{Cardiac NCX structure and function}

Since 1990, molecular biology techniques applied to the study of the NCX have given abundant information on its structure-function relationships. The canine cardiac NCX1 subtype was the first to be purified and cloned $[12,13]$. Further subtypes that are products of different genes (NCX2 and NCX3) were later found in the brain and skeletal muscles, whereas NCX1 is universally distributed practically in every mammalian cell. The cardiac NCX1 consists of 970 amino acids with a molecular mass of $110 \mathrm{kDa}$ [13]. Presently, in the latest version, the $\mathrm{Na}^{+} / \mathrm{Ca}^{2+}$ exchanger contains 9 transmembrane segments, 5 from the $\mathrm{NH} 2$ terminus up to the large intracellular loop 


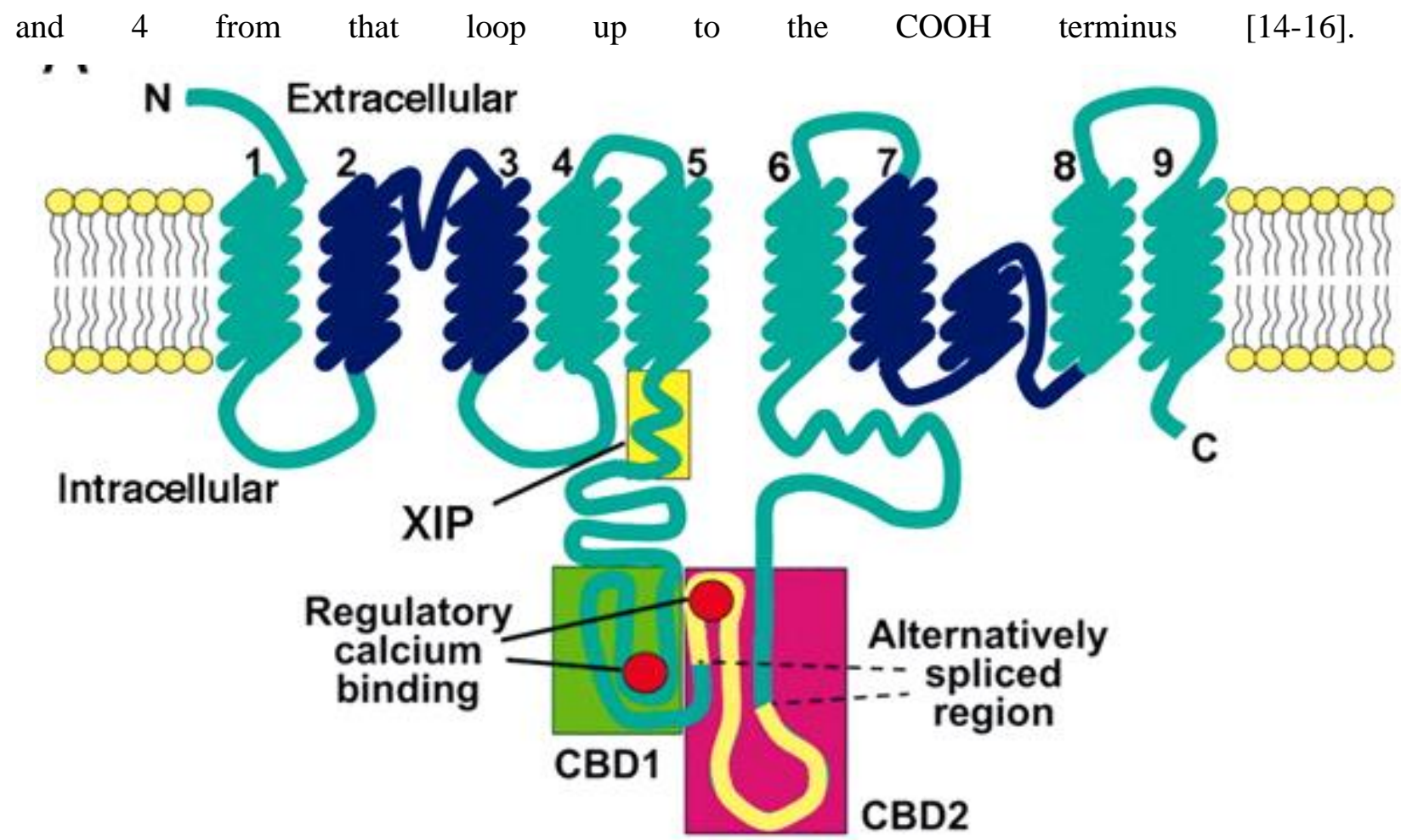

Fig. 2: Overall topology of NCX1. The $N$ and $C$ termini, reentrant loops (in blue), XIP region, and CBD1 and CBD2, including the alternatively spliced region.

The NH2-terminal portion of the loop has a 20-amino acid domain rich in hydrophobic and basic amino acids and is called the XIP (exchange inhibitor peptide) region; in addition, it has an overall amino acid sequence similar to the calmodulin-binding domain [16]. This region is associated with the $\mathrm{Na}_{\mathrm{i}}$ inactivation process. Around the central zone of the loop, there is a sequence of 135 amino acid containing highly acidic residues (two zones of three aspartyl each) that bind $\left[\mathrm{Ca}^{2+}\right]_{i}$ with high affinity; this region is responsible for the $\left[\mathrm{Ca}^{2+}\right]_{i}$-dependent or allosteric regulation of the exchanger [17]. In cardiac muscle, one of the isoforms of the sodium calcium exchanger, NCX1, represents a major system of extrusion of $\mathrm{Ca}^{2+}$ that enters the cell by L-type $\mathrm{Ca}^{2+}$ channels (Cav1.2). Like other $\mathrm{Ca}^{2+}$ transport systems which are involved in excitationcontraction coupling (Cav1.2 and $\mathrm{Ca}^{2+}$ release channels of SR), NCX1 is regulated by intracellular $\mathrm{Ca}^{2+}$.

In cardiac myocytes, function of the $\mathrm{Na}^{+} / \mathrm{Ca}^{2+}$ exchanger belongs to the most important mechanisms of the $\mathrm{Ca}^{2+}$ homeostasis, and displays a major contribution to the regulation of the $\mathrm{Ca}^{2+}$ level during the cardiac excitation-contraction coupling. The major function of the NCX in the heart is the extrusion of $\mathrm{Ca}^{2+}$ from cytoplasm during relaxation and diastole. The major source of $\mathrm{Ca}^{2+}$ triggering the $\mathrm{Ca}^{2+}$ cycle is the L-type $\mathrm{Ca}^{2+}$ current which flows into the cell at the beginning of the action potential. In this phase of the action potential, the NCX can contribute to 
the $\mathrm{Ca}^{2+}$ influx into the cell since the membrane potential is positive and the intracellular $\mathrm{Ca}^{2+}$ level is low. However, when the intracellular $\mathrm{Ca}^{2+}$ level increases at the beginning of the $\mathrm{Ca}^{2+}$ transient due to the $\mathrm{Ca}^{2+}$-induced release of $\mathrm{Ca}^{2+}$ from the sarcoplasmic reticulum, the NCX turns into its forward mode operation, thereby contributing to the extrusion of $\mathrm{Ca}^{2+}$ from the cell. Relaxation of the $\mathrm{Ca}^{2+}$ transient is a result of the activities of tree competing mechanisms. $70-90 \%$ of the cytoplasmic $\mathrm{Ca}^{2+}$ is resequestrated into the sarcoplasmic reticulum by the sarcoplasmic reticulum $\mathrm{Ca}^{2+}$-ATPase, 7-30\% is extruded from the cell by the NCX, and only a small amount of $\mathrm{Ca}^{2+}$ is extruded by the slow $\mathrm{Ca}^{2+}$-transport systems, such as the sarcolemmal $\mathrm{Ca}^{2+}$-ATPase and the mitochondrial $\mathrm{Ca}^{2+}$-transport.

\subsection{Intracellular $\mathrm{Na}^{+}$and $\mathrm{pH}$ regulation}

\subsubsection{Intracellular pH Regulation in the Cardiac Cell}

Cardiac myocytes expresses the apparatus for $\mathrm{pH}_{\mathrm{i}}$ regulation by which an acute displacement of $\mathrm{pH}_{\mathrm{i}}$ is compensated within minutes. The recovery of $\mathrm{pH}_{\mathrm{i}}$ is mediated by sarcolemmal ion transport proteins that move $\mathrm{H}^{+}, \mathrm{OH}^{-}$or $\mathrm{HCO}_{3}{ }^{-}$ions across the membrane. It should be noted that influx of one $\mathrm{HCO}_{3}{ }^{-}$anion, by neutralising an intracellular $\mathrm{H}^{+}$ion (thereby forming $\mathrm{CO}_{2}$, which escapes from the cell), raises $\mathrm{pH}_{\mathrm{i}}$ by the same amount as the direct efflux of one $\mathrm{H}^{+}$ion (or the influx of one $\mathrm{OH}^{-}$ion). These ion transport steps are thus referred to as $\mathrm{H}^{+}$-equivalent ion movements. At least five generic types of $\mathrm{H}^{+}$-equivalent transport protein have been identified functionally in the mammalian ventricular myocyte. $\mathrm{Na}^{+} / \mathrm{H}^{+}$exchange (NHE) and $\mathrm{Na}^{+} / \mathrm{HCO}_{3}{ }^{-}$cotransport (NBC) mediate acid-extrusion while $\mathrm{Cl}^{-} / \mathrm{HCO}_{3}{ }^{-}$exchange $(\mathrm{CBE})$ and $\mathrm{Cl}^{-} / \mathrm{OH}^{-}$exchange (CHE) mediate acid loading. A lactate- $\mathrm{H}^{+}$cotransport (monocarboxylate transporter, MCT) operates in either efflux or influx mode, depending on zhe actual circumstances. Under normoxic, non-exercise conditions lactate concentrations are low so that sarcolemmal MCT is largely inactive. During hypoxia, however, when lactate levels are high, its influence on $\mathrm{pH}_{\mathrm{i}}$ becomes significant. At normal physiologic $\mathrm{pH}$, all four regulators have low activity. When intracellular $\mathrm{pH}$ rises, the acid loaders are activated, restoring intracellular $\mathrm{pH}$ through an influx of acid. When intracellular $\mathrm{pH}$ falls, the acid extruders are activated, restoring intracellular $\mathrm{pH}$ by removing acid [18].

\subsubsection{Structure of NHE}

The $\mathrm{Na}^{+} / \mathrm{H}^{+}$exchangers (NHEs) are a family of integral membrane glycoproteins expressed ubiquitously in mammalian cells, and it electroneutrally exchanges intracellular $\mathrm{H}^{+}$for extracellular $\mathrm{Na}^{+}(1: 1)$ to regulate intracellular $\mathrm{pH}\left(\mathrm{pH}_{\mathrm{i}}\right)$ and the concentration of $\left[\mathrm{Na}^{+}\right]_{\mathrm{i}}[19]$. The NHE-1 isoform is ubiquitously distributed in most tissues and is the primary NHE subtype found 
in the mammalian cardiac cell. NHE-1, the first isoform to be cloned, is expressed ubiquitously in the plasma membrane and is considered to be the cardiac-specific isoform [20].

NHE-1 is expressed, whereas a more restricted pattern of expression is shown for NHE-2 through NHE-5. Both NHE-6 and NHE-7 are intracellularly localized, although their functions are not currently known.

\subsection{Effect of Ischaemia on Cellular Sodium and Calcium Homeostasis}

Myocardial ischemia occurs when the energy demands of the cardiac tissue are not met by the available energy substrates. In most cases pathological conditions, this occurs with the sudden occlusion of a coronary artery by a thrombus, a situation that frequently culminates in lifethreatening arrhythmia and sudden death [21]. Deprivation of oxygen and nutrient supply results in a series of biochemical and metabolic changes within the myocardium. The absence of oxygen halts oxidative phosphorylation, leading to mitochondrial membrane depolarization, ATP depletion, and inhibition of myocardial contractile function. This process is exacerbated by the breakdown of the available ATP, as the $\mathrm{F}_{1} \mathrm{~F}_{0}$ ATPase function reverses to maintain the mitochondrial membrane potential, resulting in ATP hydrolysis and an increase in mitochondrial inorganic phosphate. In the absence of oxygen, cellular metabolism switches to anaerobic glycolysis, resulting in the accumulation of lactate, which reduces intracellular $\mathrm{pH}$ (to <7.0). The acidic conditions during ischemia prevent the opening of the MPTP and cardiomyocyte hypercontracture at this time. The intracellular accumulation of protons activates the $\mathrm{Na}^{+}-\mathrm{H}^{+}$ion exchanger, which extrudes protons from the cell in exchange for $\mathrm{Na}^{+}$entry. The lack of ATP during ischemia ceases function of the $\mathrm{Na}^{+}-\mathrm{K}^{+}$ATPase, thereby exacerbating the intracellular $\mathrm{Na}^{+}$ overload. In response, the reverse activation of the NCX results in intracellular $\mathrm{Ca}^{2+}$ overloading as the cell tries to extrude $\mathrm{Na}^{+}$.

This contributes to intracellular $\mathrm{Ca}^{2+}$ overload and damages the cell membrane by lipid peroxidation, inducing enzyme denaturation and causing direct oxidative damage to DNA. Reperfusion and reactivation of the NHE result in washout of lactic acid, resulting in the rapid restoration of physiological $\mathrm{pH}$, which releases the inhibitory effect on MPTP opening and cardiomyocyte contracture. The restoration of the mitochondrial membrane potential drives calcium into the mitochondria, which can also induce MPTP opening [22]. 


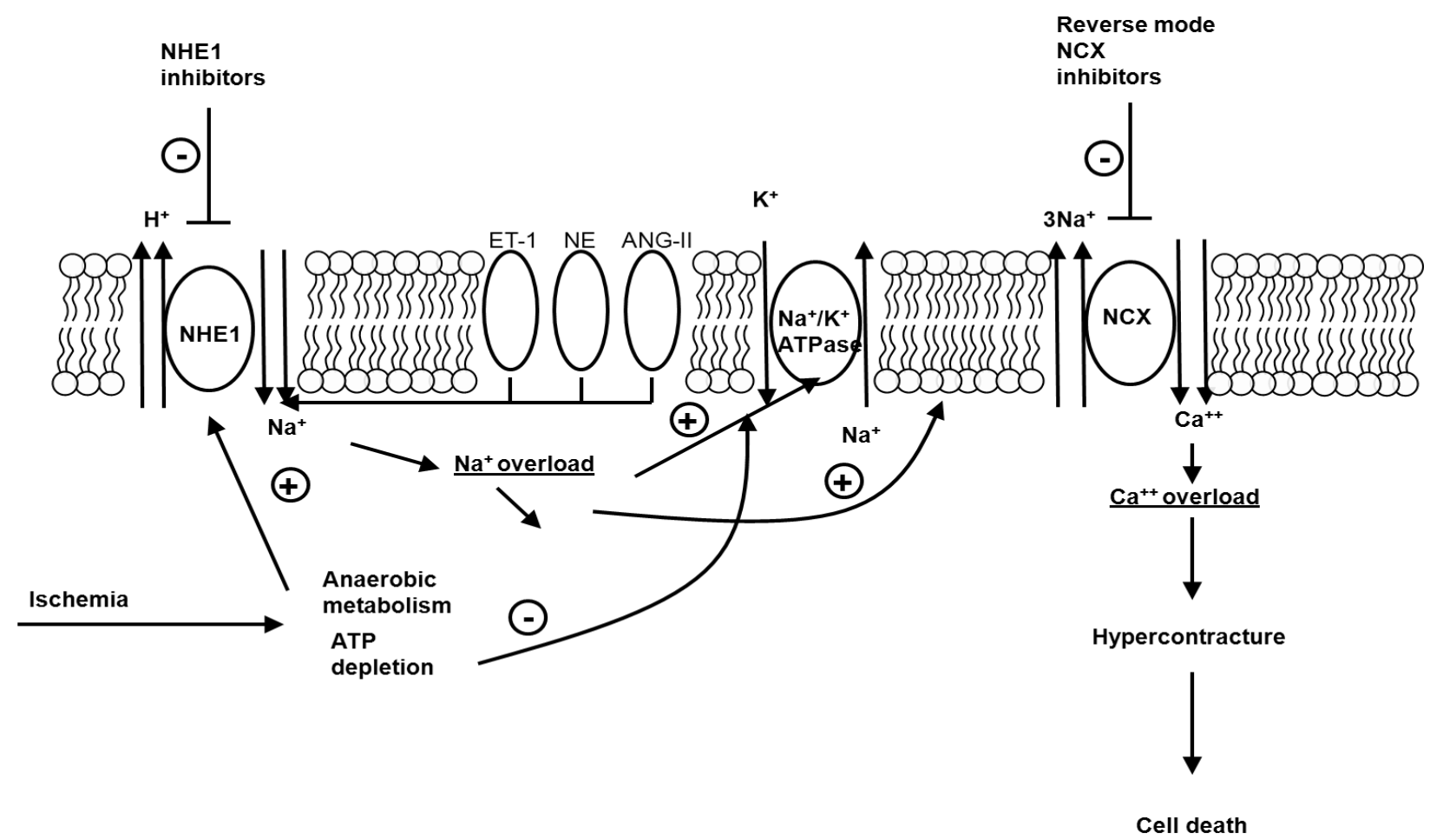

Fig. 3: Causes and consequences of ionic imbalances during ischemia. Ischaemia results in a cessation of aerobic metabolism and a reliance on anaerobic metabolism, resulting in cellular and tissue acidosis. Accumulation of intracellular $\mathrm{H}^{+}$stimulates $\mathrm{NHE}$, resulting in accumulation of intracellular $\mathrm{Na}^{+}$. Accumulation of intracellular $\mathrm{Na}^{+}$, in turn, stimulates reverse activity of the $\mathrm{NCX}$, resulting in intracellular $\mathrm{Ca}^{2+}$ accumulation. $\mathrm{NHE}, \mathrm{Na}^{+} / \mathrm{H}^{+}$exchanger; $\mathrm{NCX}, \mathrm{Na}^{+} / \mathrm{Ca}^{2+}$ exchanger.

\subsubsection{Consequences of a pathophysiologically increased late $I_{\mathrm{Na}}$}

A pathophysiologically increased late $\mathrm{I}_{\mathrm{Na}}$ by itself can alter cellular electrophysiology by two distinguished ways and thus increase the propensity for arrhythmias, i.e. elevation of late $I_{\mathrm{Na}}$ a) prolongs the cardiac action potentials, and b) causes cellular $\mathrm{Na}$-dependent $\mathrm{Ca}$ overload. EADs are more likely to occur during a prolonged action potential duration, which can be induced by enhancing late $\mathrm{I}_{\mathrm{Na}}$. Moreover, transmural differences in late $\mathrm{I}_{\mathrm{Na}}$, and hence action potential duration, might increase transmural dispersion of repolarization and QT interval, which underlies the development of torsade de pointes arrhythmias [20]. In contrast, calcium overload, which occurs when late $\mathrm{I}_{\mathrm{Na}}$ is elevated [12], and leakiness of the cardiac ryanodine receptor are believed to participate in the initiation of spontaneous sarcoplasmic reticulum calcium release events and/or proarrhythmogenic Ca waves [43]. The consequence is the elimination of the released $\mathrm{Ca}$ via the NCX, which generates the transient inward current, $\mathrm{I}_{\mathrm{Ti}}$, which can give rise to DADs [44]. It has been that late $\mathrm{I}_{\mathrm{Na}}$ plays a crucial role iarrhythmia generation in guinea pig atrial myocytes [45]. They observed EADs and DADs as well as triggered activity. Also, elevation of late $\mathrm{I}_{\mathrm{Na}}$ induced a Ca-dependent $\mathrm{I}_{\mathrm{Ti}}$. Calcium chelating agents, NCX blockers, and the sarcoplasmic reticulum $\mathrm{Ca}$ release inhibitor ryanodine could prevent DADs and triggered activity. Because 
EADs could not be prevented using these agents, it is suggested that action potential prolongation causes EADs in a Ca-independent manner.

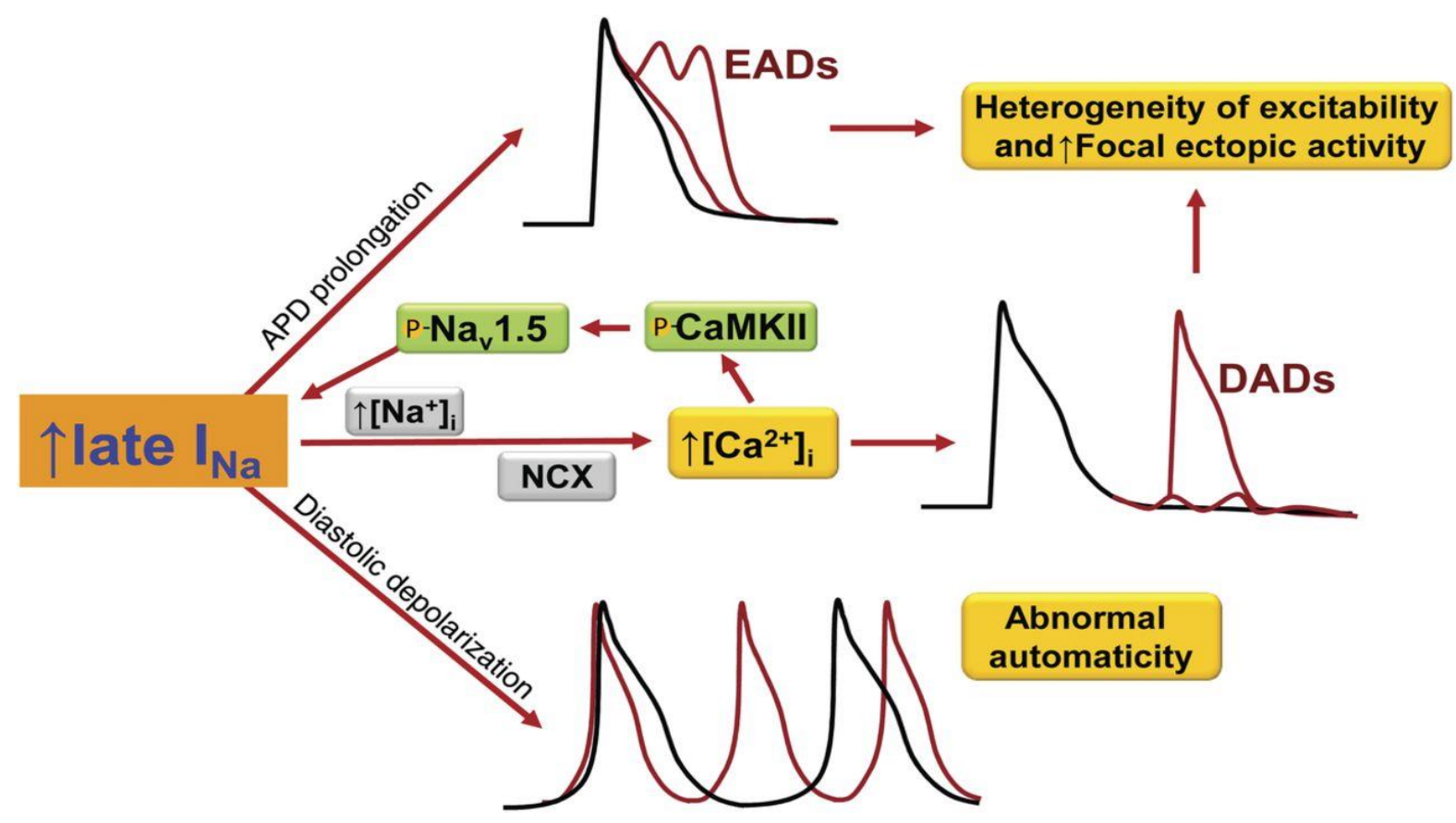

Fig.4: Mechanisms of late $I_{N a}$-induced arrhythmia: EADs, DADs, and spontaneous diastolic depolarization. Not shown, late $I_{N a}$ increases spatiotemporal dispersion of repolarization and facilitates reentrant arrhythmic activity. $\mathrm{NCX}, \mathrm{Na}^{+} / \mathrm{Ca}^{2+}$ exchange; CaMKII, $\mathrm{Ca}^{2+} /$ calmodulin-dependent protein kinase II.

\subsection{Cardiac action potential}

Upon activation cardiomyocytes are depolarized by a rapid inflow of $\mathrm{Na}^{+}$ions generating a large and fast inward $\mathrm{Na}^{+}$current $\left(\mathrm{I}_{\mathrm{Na}}\right)$. $\mathrm{I}_{\mathrm{Na}}$ not only defines the rapid upstroke of the AP (phase 0 ) but has also primary role in defining the velocity of impulse propagation through the heart. The initial depolarization of the AP is followed by a transient repolarization (phase 1) mainly governed by the transient outward current $\left(\mathrm{I}_{\mathrm{to}}\right)$. In this section of the AP, the $\mathrm{Ca}^{2+}$-activated $\mathrm{Cl}^{-}$current $\left(\mathrm{I}_{\mathrm{Cl}(\mathrm{Ca})}\right.$ or $\mathrm{I}_{\mathrm{to} 2}$ ) is also suggested to contribute to the transient repolarization. The rapid upstroke of the AP activates the L-type $\mathrm{Ca}^{2+}$ current $\left(\mathrm{I}_{\mathrm{CaL}}\right)$ and also several crucial $\mathrm{K}^{+}$currents involved in the repolarization: i.e. the rapid and slow components $\left(\mathrm{I}_{\mathrm{Kr}}\right.$ and $\mathrm{I}_{\mathrm{Ks}}$ ) of the delayed rectifier $\mathrm{K}^{+}$current and the inward rectifier $\mathrm{K}^{+}$current $\left(\mathrm{I}_{\mathrm{K} 1}\right)$. During a period of time $\mathrm{I}_{\mathrm{CaL}}$ opposes the outward repolarizing currents, establishing a nearly isoelectric plateau phase (phase 2) of the AP. The duration of the plateau phase has important role in controlling the amount of the $\mathrm{Ca}^{2+}$ influx. The $\mathrm{Ca}^{2+}$ influx has crucial role in initializing the intracellular $\mathrm{Ca}^{2+}$ cycle leading to contraction of the cell. When $\mathrm{Ca}^{2+}$ channels begin to close the outward currents gradually overcame $\mathrm{I}_{\mathrm{CaL}}$, enabling fast repolarization of the AP (phase 3), governed by cooperative function of $\mathrm{I}_{\mathrm{Ks}}$, $\mathrm{I}_{\mathrm{Kr}}$, and $\mathrm{I}_{\mathrm{K} 1}$. The 
terminal repolarization (phase 4) of the AP, as well as the resting membrane potential is primarily controlled by the $\mathrm{I}_{\mathrm{K} 1}$. In normal myocytes $\mathrm{Ca}^{2+}$ influx via $\mathrm{NCX}$ (outward $\mathrm{I}_{\mathrm{NCX}}$ ) is only expected for a very brief period early during the AP. The rise in submembrane $\left[\mathrm{Ca}^{2+}\right]_{\mathrm{i}}\left(\left[\mathrm{Ca}^{2+}\right]_{\mathrm{sm}}\right)$ quickly favors inward $\mathrm{I}_{\mathrm{NCX}}\left(\mathrm{Ca}^{2+}\right.$ efflux $)$.

\subsection{Pharmacology of NCX}

Potent and selective blockers of NCX activity would be extremely useful for clarifying the precise functions of NCX. Until recently, however, this possibility was hampered in case of NCX because of the lack of potent and highly specific inhibitors.

Because NCX moves ions and charge in either direction, mode-specific inhibitors of NCX, if available, may have high therapeutic potential. For example, specific blocking of excessive $\mathrm{Ca}^{2+}$ influx via reverse-mode NCX activity may reduce $\mathrm{Ca}^{2+}$ overload due to cardiac glycoside toxicity or to ischemia and reperfusion in the heart and other tissues. Increased $\mathrm{Ca}^{2+}$ influx via NCX is also implicated in some forms of hypertension [23]. In heart failure, enhanced $\mathrm{Ca}^{2+}$ efflux due to upregulation of NCX activity may impair the systolic function by reducing the SR $\mathrm{Ca}^{2+}$ loading and is also directly implicated as a cause of arrhythmias [24]. On the other hand, excess $\mathrm{Ca}^{2+}$ influx via NCX during the terminal phase of the action potential plateau could contribute to the slow relaxation in failing myocytes [25]. However, to what extent mode-specific blockers of NCX may be beneficial in therapeutic control of the overall function of a failing heart and/or other diseased organs remains to be determined. As blockers of NCX activity, many divalent and trivalent cations, such as $\mathrm{La}^{3+}, \mathrm{Ni}^{2+}$, and $\mathrm{Cd}^{2+}$, and a variety of organic compounds, including amiloride derivatives (eg, dichlorobenzamil) or the substituted pyrolidine ethanamine (eg, bepridil), have long been known. These cations and organic agents also exert inhibitory effect on other ion channels and/or transporters, which limits their use as specific blockers of NCX activity. Nowadays, the two most selective and widely used NCX inhibitors in the literature are the aniline derivative, SEA0400 and KB-R7943 [26]. Intriguingly, KB-R7943 exerts a preferential effect on reverse-mode $\left(\mathrm{Ca}^{2+}\right.$-influx mode) NCX activity. However, the selective blocking of $\mathrm{Ca}^{2+}$ influx via NCX is observed irrespective of the presence or absence of extracellular $\mathrm{Ca}^{2+}$. In cardiac sarcolemmal vesicles, the XIP peptide and a $\mathrm{Ca}^{2+}$ channel blocker, nicaldipine, depressed the rate of $\mathrm{Na}^{+}$-dependent $\mathrm{Ca}^{2+}$ uptake much more potently than that of $\mathrm{Na}^{+}$-dependent $\mathrm{Ca}^{2+}$ efflux. Although the data suggest a significant difference in the properties of NCX1 in the forward and reverse modes, the underlying molecular mechanism for this peculiar directional specificity is not clear.

The other selective inhibitor of $\mathrm{Na}^{+} / \mathrm{Ca}^{2+}$ exchange SEA0400 was up to 100 times more potent than KB-R7943. At $1 \mu \mathrm{M}$ SEA0400 was reported to have no effect on $\mathrm{Na}^{+}$, L-type $\mathrm{Ca}^{2+}$, inwardly 
rectifying $\mathrm{K}^{+}$, and delayed rectifier $\mathrm{K}^{+}$currents in isolated guinea pig ventricular myocytes. However, at $10 \mu \mathrm{M}$, SEA0400 partially inhibited the L-type $\mathrm{Ca}^{2+}$ current. In isolated canine ventricular myocytes, Biliczki et al. found that SEA0400 $(1 \mu \mathrm{M})$ decreases NCX current without any significant effects on $I_{\mathrm{to}}, I_{\mathrm{Ks}}, I_{\mathrm{Kr}}$, or $I_{\mathrm{K} 1}$. At concentrations of $\leq 1 \mu \mathrm{M}$ SEA0400 had no effect on cardiac function in isolated rabbit hearts. At $1 \mu \mathrm{M}$ SEA0400 significantly improved the first derivative of left ventricular pressure $( \pm d P / d t)$ after ischemia as reported in the same study. Because of its limited solubility, SEA0400 has not been evaluated at higher concentrations [27].

Some synthetic peptides are also effective NCX inhibitors. The XIP peptide derived from the primary sequence of cardiac NCX1 decreases the $\mathrm{V}_{\max }$ of NCX activity. As noted earlier, it is significantly less potent in inhibiting Na-dependent $\mathrm{Ca}^{2+}$ efflux from sarcolemmal vesicles than in inhibiting the reverse reaction. XIP has little effect on $\mathrm{Na}^{+} / \mathrm{K}^{+}$-ATPase, SR $\mathrm{Ca}^{2+}$-ATPase, or Ltype $\mathrm{Ca}^{2+}$ currents, and it does not increase membrane conductance when applied to the intracellular surface by use of the excised-patch technique [16]. However, it may bind calmodulin and could thus interfere with the function of calmodulin- binding proteins. Furthermore, its usefulness as an NCX inhibitor is limited because it acts only from the cytoplasmic side.

Other peptides, such as the molluscan cardioexcitatory tetrapeptide Phe-Met-Arg-Phe-NH2 (FMRFa) and its analogues and the cyclic hexapeptide Phe-Arg-Cys-Arg-Cys- Phe-CONH2 (FRCRCFa), which are much smaller than XIP, have been reported to inhibit NCX activity [28]. FMRFa and its related peptides inhibit the NCX activity of cardiac sarcolemmal vesicles. On the basis of structure/activity studies of these peptides, a new cyclic peptide, FRCRCFa, with an intramolecular disulfide bond has been synthesized. FRCRCFa exhibits improved inhibitory potency and resistance to proteolytic degradation, and in sarcolemmal vesicles it inhibits NCX activity completely,without competing with extravesicular $\mathrm{Ca}^{2+}$ and $\mathrm{Na}^{+}$. In the rabbit ventricular myocyte, FRCRCFa inhibits whole-cell NCX currents much more potently, and exhibits a rapid onset of action. Furthermore, it reportedly has no effect on L-type $\mathrm{Ca}^{2+}$ channels or delayed rectifier and inward rectifier $\mathrm{K}_{1}$ channels. Thus, FRCRCFa appears to have several advantages over XIP. This peptide acts from the intracellular side, but its binding site has not been identified. Iwamoto and colleagues [29] describe the characterization of a new NCX inhibitor, SN-6, a derivative of KB-R7943. As reported recently for SEA0400, SN-6 seems to act by accelerating $\mathrm{Na}^{+}$-dependent inactivation, thereby preferentially inhibiting the "reverse" mode transport that occurs with elevated intracellular $\mathrm{Na}^{+}$during hypoxia. The extent to which $\mathrm{SN}-6$ is specific for NCX remains uncertain because both KB-R7943 and SEA0400 displayed similar specificity on an initial screen of receptors and channels; however, both drugs depressed $\mathrm{Ca}^{2+}$ transients in myotubes from NCX1 knockout mice, suggesting that they are not completely specific for NCX. 
This may be an important caveat for experimental uses of these drugs but may not affect their therapeutic potential in humans.

In conclusion, although there are several pharmacological agents inhibiting the NCX, the interpretation of results obtained using these compounds is complicated by the concomittant effects on other transport systems or ionic channels.

\subsection{Cardioprotective Effects of NCX and NHE inhibitor}

A reasonable defensive strategy to limit the ischaemia/reperfusion-induced $\left[\mathrm{Na}^{+}\right]_{\mathrm{i}}$ accumulation and subsequent $\left[\mathrm{Ca}^{2+}\right]_{\mathrm{i}}$ overload seems to be a pharmacological inhibition of one or both exchangers. However, since their normal activity is vital, only a partial and temporal blockade may be safely introduced. In preclinical studies, NHE inhibition has been shown to be highly effective, especially when applied before ischaemia [30-33]. Based on the promising results of these studies, NHE inhibition has been suggested as a straightforward therapeutic strategy against ischaemia-reperfusion-induced cardiac injuries. Human results from phase2/phase 3 clinical trials (GUARDIAN, EXPEDITION, ESCAMI), however, produced disappointing results, reporting only limited efficacy of this strategy in the majority of cases [34].

Theoretically, NCX inhibitors administered shortly after the onset of a heart attack might reduce the probability of arrhythmia generation by limiting damage in the border zone. In a range of preclinical studies, especially under moderate ischaemia, reverse mode inhibition of NCX has been found to suppress both $\left[\mathrm{Na}^{+}\right]_{i}$ and $\left[\mathrm{Ca}^{2+}\right]_{i}$ overload, hypercontracture, enzyme release and cell damage [35]. Consequently, the inhibition of NCX may have substantial therapeutic potential in the prevention of cardiac ischaemia/reperfusion-induced arrhythmias and injuries [36]. Evaluation of the experimental data on NCX inhibition was, however, seriously hampered by the lack of selective and highly effective NCX inhibitors. This may explain why only NHE inhibitors are used to some extent in clinical practice. NCX inhibitors have never been tested in clinical trials.

In summary, there is convincing evidence suggesting that in clinical practice, NHE inhibition, per $s e$, fails to prevent or substantially reduce ischaemia/reperfusion-induced arrhythmogenesis [37]. On the other hand, reverse mode NCX inhibition displayed promising cardioprotective effects in animal studies [38]. The present work was based on the assumption, that since the enhanced NHE activity is only one factor resulting in cardiac arrhythmogenesis due to the subsequent $\left[\mathrm{Ca}^{2+}\right]_{\mathrm{i}}$ overload, the inhibition of NHE itself, does not seem to be the optimal treatment to reduce the incidence and severity of cardiac arrhythmias. One may also speculate that since the NHE and NCX seem to play a joint key role in the induction of ischaemia/reperfusion-induced $\left[\mathrm{Ca}^{2+}\right]_{\mathrm{i}}$ 
overload, the deteriorative effects might be better attenuated by simultaneously inhibiting both the NHE and NCX.

\section{AIMS OF THE STUDY}

The primary aim of our studies was the detailed analysis of the cardioprotective effects of NCX and/or NHE blockade against $\left[\mathrm{Na}^{+}\right]_{i}$ rise induced $\left[\mathrm{Ca}^{2+}\right]_{i}$ overload and subsequent changes in action potential morphology in experimental models of LQT3 syndrome and ischaemia/reperfusion injury. The major questions were:

- Can SEA0400 or ORM-10103 prevent ATX-II induced changes in AP morphology and APD prolongation?

- Is individual or combined inhibition of NHE and/or NCX protective following regional ischaemia, against arrhythmias, at least partially generated by reperfusion-induced $\left[\mathrm{Ca}^{2+}\right]_{\mathrm{i}}$ overload in Langendorff - perfused rat hearts?

- Does NCX and/or NHE inhibition have a protective effect on $\mathrm{Ca}^{2+}$ overload induced contracture during and following global ischaemia?

For this purpose, a well-known, well-characterised NHE inhibitor, cariporide [39], and two NCX inhibitors, the fairly selective SEA0400 [40] and the novel, more selective ORM-10103 [41], were used.

\section{METHODS AND MATERIALS}

All experiments were performed in compliance with the Guide for the Care and Use of Laboratory Animals (USA NIH publication No. 86-23 revised 1996) and fully conformed to Directive 2010/63/EU of the European Parliament. Experimental protocols were approved by the Ethics Committee for the Protection of Animals in Research of the University of Szeged, Szeged, Hungary (permit No. I-74-9/2009).

\subsection{Preparation of papillary muscles}

Canine papillary muscles were isolated from adult mongrel dogs of either sex weighing 10 to $20 \mathrm{~kg}$. Following sedation (xylazine, $1 \mathrm{mg} / \mathrm{kg}$, i.v.) the animals were anaesthetized with $30 \mathrm{mg} / \mathrm{kg}$ thiopental and anticoagulated with sodium-heparin. The proper depth of anesthesia was carefully tested with pupil and pain reflexes. After right lateral thoracotomy the heart was quickly removed and immediately rinsed in oxygenated modified Locke's solution containing (in $\mathrm{mM}$ ): $\mathrm{Na}^{+} 140, \mathrm{~K}^{+} 4$, 
$\mathrm{Ca}^{2+} 1.0, \mathrm{Mg}^{2+} 1, \mathrm{Cl}^{-} 126, \mathrm{HCO}_{3} 25$ and glucose 11 . The $\mathrm{pH}$ of the solution, bubbled with $95 \% \mathrm{O}_{2}$ and $5 \% \mathrm{CO}_{2}$ at $37^{\circ} \mathrm{C}$, ranged from 7.35 to 7.45 .

\subsection{Preparation of isolated hearts}

Male Sprague-Dawley rats $(250$ - $350 \mathrm{~g})$ were anaesthetised with sodium thiopental $(0.1 \mathrm{~g} / \mathrm{kg}$, i.p.) and injected with heparin sodium (500 IU i.v.). Hearts were rapidly excised, mounted via the aorta on a Langendorff apparatus and perfused retrograde with warm $\left(37^{\circ} \mathrm{C}\right)$, modified KrebsHenseleit bicarbonate (KHB) buffer at a constant pressure $(80 \mathrm{mmHg})$. The KHB solution contained (in mmol/l): $\mathrm{NaHCO}_{3} 25 ; \mathrm{KCl} 4.3 ; \mathrm{NaCl} 118.5 ; \mathrm{MgSO}_{4} 1.2 ; \mathrm{KH}_{2} \mathrm{PO}_{4}$ 1.2; Na-pyruvate 5; glucose $11 ; \mathrm{CaCl}_{2} 2$, having a $\mathrm{pH}$ of $7.4 \pm 0.05$ when gassed with carbogene $\left(95 \% \mathrm{O}_{2}+5 \%\right.$ $\mathrm{CO}_{2}$ ). For the induction of regional ischaemia, a $6 / 0$ braided silk suture was placed around the left anterior descending coronary artery (LAD). A water-filled latex balloon was inserted into the left ventricular cavity and inflated to obtain a control state end-diastolic pressure (LVEDP) of 4-8 mmHg. Coronary flow (CF), left ventricular pressure (LVP), perfusion pressure, and the electrocardiogram (ECG) were simultaneously recorded using the Haemosys software (Experimetria, Hungary). Left ventricular contractility $\left( \pm \mathrm{dP} / \mathrm{dt}_{\max }\right)$ and heart rate $(\mathrm{HR})$ were calculated off-line from the recorded LVP curve.

\subsection{Experimental protocol}

\subsubsection{Recording of action potentials in multicellular preparations}

Isolated papillary muscles were obtained from the right ventricle. Multicellular preparations were mounted in a $40 \mathrm{ml}$ glass chamber and perfused with Krebs-Henseleit solution at $37^{\circ} \mathrm{C}$. The recording pipette was filled with $3 \mathrm{M} \mathrm{KCl}$. SEA0400 has been applied in $1 \mu \mathrm{M}$ concentration. At this concentration its inhibitory effect on $I_{C a}$ was 20\%.[40] ORM10-103 has been applied in concentration of $10 \mu \mathrm{M}$ in which in can exert its maximal inhibitory effect without influencing the $\mathrm{Ca}^{2+}$ current [41].

The effect of upregulating $\mathrm{I}_{\mathrm{NaL}}$ using ATX-II, which is known to increase substantially the $\mathrm{Na}^{+}$ influx due to lengthening of the inactivation of $\mathrm{I}_{\mathrm{NaL}}$. Application of $2 \mathrm{nM}$ ATX-II significantly increased the amplitude of the AP. ATX-II binds to the open state of the cardiac sodium channel, thereby slowing channel inactivation and facilitating channel re-opening from the closed state. ATX-II increases both total and late inward depolarizing so-dium current during the action potential plateau. ATX-II increases the duration of the ventricular myocyte action potential and can induce both early afterdepolarizations (EADs) and ventricular tachycardia. 
Cardiac pathologies are associated with increased late $\mathrm{I}_{\mathrm{Na}}$ that contributes to the dysregulation of ion homeostasis and causes electrical and contractile dysfunction. This study was designed to test the hypothesis that an increased late sodium channel current $\left(\mathrm{I}_{\mathrm{Na}}\right)$ leads to $\mathrm{Ca}^{2+}$ overload and left ventricular (LV) dysfunction, and thereby inhibition of late $\mathrm{I}_{\mathrm{Na}}$ improves $\mathrm{Ca}^{2+}$ homeostasis and reduces LV dysfunction.

\subsubsection{Global ischemia}

Isolated hearts were perfused for 10 minutes to establish stable baseline performance before 5 minutes perfusion of the inhibitors. For the induction of the no-flow global ischaemia, the perfusion completely stopped for a duration of 25 minutes followed by 50 minute reperfusion. Hearts were randomly assigned into 4 experimental groups: the control (CON) group was perfused with KHB solution containing solely the vehicle (dimethyl sulphoxide (DMSO) in $0.01 \%$ final concentration). Two heart groups were perfused with KHB solution containing only a single inhibitor: $5 \mu \mathrm{M}$ cariporide (CAR); $1 \mu \mathrm{M}$ SEA0400 (SEA) and 1 experimental group was treated with a combination of the NHE and NCX inhibitors: $5 \mu \mathrm{M}$ cariporide $+1 \mu \mathrm{M}$ SEA0400 $(\mathrm{SEA}+\mathrm{CAR})$.

We observed more the the ischemia-induced contracture's parameters: the moments when the maximal contracture's occuring, the amplitude of contracture and the rate of the contracture in the 25. ischaemic minute.

\subsubsection{Regional ischaemia}

All hearts were allowed to stabilise for $\mathbf{1 0} \mathrm{min}$. The perfusion of drugs or vehicle started $\mathbf{5}$ minutes before occlusion of the left anterior descending coronary artery (LAD) and were maintained throughout the protocol. Hearts were randomly assigned into six experimental groups: the control $(\mathrm{CON})$ group was perfused with KHB solution containing solely the vehicle (dimethyl sulphoxide (DMSO) in $0.01 \%$ final concentration). Three heart groups were perfused with KHB solution containing only a single inhibitor: $5 \mu \mathrm{M}$ cariporide (CAR); $1 \mu \mathrm{M}$ SEA0400 (SEA) or 1 $\mu \mathrm{M}$ ORM-10103 (ORM). Two experimental groups were treated with a combination of the NHE and NCX inhibitors: $5 \mu \mathrm{M}$ cariporide $+1 \mu \mathrm{M}$ SEA0400 (SEA+CAR) or with $5 \mu \mathrm{M}$ cariporide +1 $\mu \mathrm{M}$ ORM-10103 (ORM+CAR). Ischaemia-reperfusion-induced arrhythmias were evoked by pulling on the suture around the artery for 10 minutes. Successful occlusion was confirmed by a significant reduction in coronary flow. To ensure the homogeneity of ischaemic damage and to exclude possible bias due to surgical artefacts, hearts with a more than $65 \%$ decrease in coronary flow rate were excluded from the study. Furthermore, hearts developing severe arrhythmias during the ischaemic period were also excluded. The $10 \mathrm{~min}$ period of regional ischaemia was 
followed by 30 min reperfusion initiated via releasing the suture. Successful reperfusion was confirmed by an immediate increase in coronary flow. LVP and ECG were recorded and analysed off-line for duration and incidence of the sinus rhythm periods (SR), SR periods with multiple extrasystoles (ES), periods of ventricular tachycardia (VT), defined by the incidence of four or more consecutive ventricular premature beats. The onset of ventricular fibrillation (VF) was verified by the permanent lack of individual QRS deflections.

\subsection{Drugs}

SEA0400 and cariporide were synthesised in the Department of Pharmaceutical Chemistry, University of Szeged. ORM-10103 was a gift from Orion Pharma (Espoo, Finland). Stock solutions were stored at $4^{\circ} \mathrm{C}$. All solutions were freshly made prior to the measurement. The inhibitory effect of both inhibitors is bidirectional with nearly symmetrical concentration dependency for the reverse and forward transport modes. All three drugs were dissolved in dimethyl-sulphoxide (DMSO) and diluted in KHB until establishing the final concentration. The DMSO concentrations in the stock solutions and in the final perfusion solution were $5 \%$ and $0.01 \%$, respectively. At this final concentration, the effect of DMSO on the heart is generally considered negligible.

In preliminary tests aimed to titrate optimal APD lengthening in multicellular samples, ATX-II (2 $\mathrm{nM}$ ) was effective, therefore, in this study we used alternatively. ATX-II is a potent neurotoxin, which modulates voltage-gated $\mathrm{Na}^{+}$channel gating kinetics by delaying its inactivation and prolonging the action potential of excitable membranes.

\subsection{Data processing and statistical analysis}

\subsubsection{Multicellular preparations:}

Statistical significances were verified using repeated measure ANOVA plus Bonferroni post hoc test. Columns and bars represent means \pm SEM, asterisks denote significant differences from control, while \# from the group pretreated with either SEA0400 or ORM-10103 ( $<<0.05)$.

\subsubsection{Global ischemia}

Experimental data were compared and analyzed using repeated measure ANOVA with Fisher LSD post hoc test. Differences were considered significant at $\mathrm{p}<0.05$.

\subsubsection{Regional ischemia}

Major haemodynamic parameters (CF, HR, LVSP, LVEDP, DP and $\pm \mathrm{dP} / \mathrm{dt}_{\max }$ ) were either directly measured or calculated from the pressure recording (LVP curve) four times during the 
experiment: at the end of the equilibration (control), pre-treatment, ischaemic and reperfusion periods, respectively. All haemodynamic values calculated for the reperfusion phase and summarised in Table 1 were obtained from hearts devoid of sustained arrhythmias or were evaluated during a period of sinus rhythm between two arrhythmic periods.

The severity of reperfusion-induced arrhythmias observed in the LVP and ECG recordings was judged by evaluating three crucial arrhythmia-related variables: the type of arrhythmic activity (i.e. extrasystoles (ES), ventricular tachycardia (VT) and ventricular fibrillation (VF)) and the incidence and duration of time periods with that arrhythmia type. Furthermore, total duration of the regular sinus rhythm periods (SR) was also calculated. It should be emphasised that although transient and sustained ventricular fibrillatory periods were both observed during the $30 \mathrm{~min}$ reperfusion period, since we were primarily interested in the efficiency of the applied pharmacological treatments against ventricular arrhythmias generated during the early phase of reperfusion, these two forms of VF were not separated during evaluation of the individual arrhythmia diagrams.

Since in many of the hearts subjected to the regional ischaemia/reperfusion protocol the ventricular fibrillation, if started, became sustained - probably, but not necessarily reflecting ischaemia-reperfusion-induced irreversible shifts in electrophysiological properties of the heart the raw values obtained for the incidence and duration of the ES and VT periods were highly dependent on the total length of the VF-free periods. Therefore, in order to provide more realistic information, the total duration of these periods has been normalised for the total duration of the VF-free periods. Furthermore, in order to avoid dividing by zero or close to zero values in cases of very low VF duration (occurring primarily in cariporide treated hearts), nominal durations of the VF periods were assigned to score levels changing in 5 min intervals between 1 and 7 (i.e. VF of 0-5 min corresponded to level 1, 5-10 min to level 2, etc.).

Unit of incidence: usually (absolute) incidence means the number of occurrences (i.e. counts); therefore, it should be dimensionless. In our analysis, relative incidence values were used, i.e. the absolute count numbers were normalised to the duration of the VF-free periods, and therefore expressed as a ratio (the occurrence divided by the total duration of VF-free periods during reperfusion). Hence, the dimension of this variable became frequency $(1 / \mathrm{min})$.

Statistical calculations were performed using Statistica 9.0 (StatSoft Inc. USA). All data are expressed as means \pm S.E.M. Statistical analysis was performed using parametric or nonparametric (Kruskal-Wallis) ANOVA, depending on the homogeneity or inhomogeneity of the variances between individual groups. All statistical calculations were performed either relative to the control group (one-way ANOVA) in case of evaluating the differences between groups with no 
treatment or various pharmacological treatments in the same experimental state (i.e. intergroup differences) or relative to the corresponding control (non-ischaemic, non-treated) baseline when evaluating the effect of interventions - i.e. the application of inhibitor(s), ischaemia or reperfusion (repeated measures ANOVA). Statistically or marginally significant differences are marked in figures by $*(p<0.05)$, or \# $(p<0.1)$, respectively.

\section{RESULTS}

\subsection{SEA0400 and ORM-10103 fail to eliminate the APD lengthening effect of ATX-II}
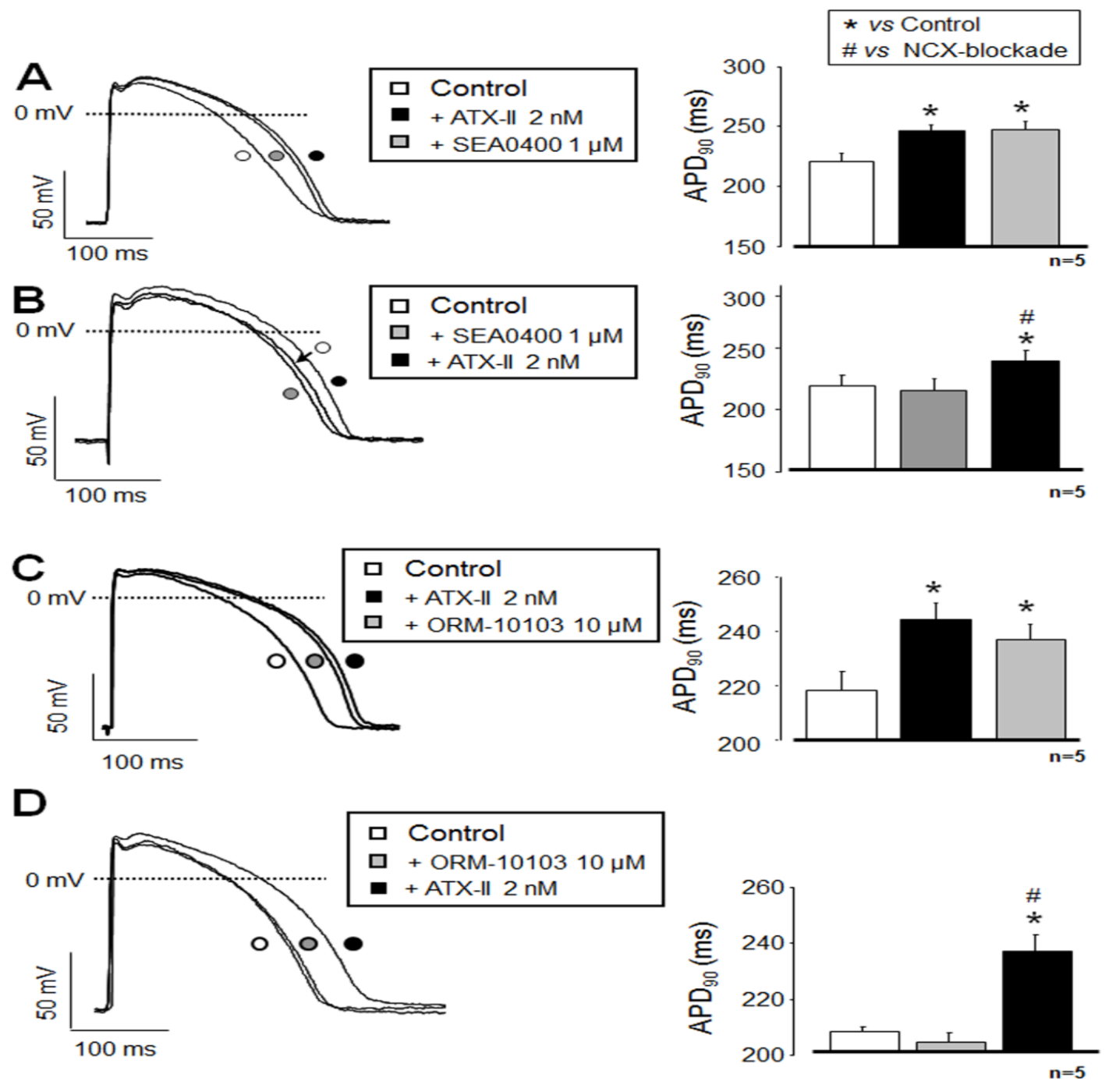

Fig.5: NCX inhibition was ineffective against the $I_{\text {NaL }}$ activation induced APD 90 prolongation. Neither SEA0400 (A, B) nor ORM-10103 (C, D) reverted or even substantially decreased the lengthening of APD, leading frequently to generation of EADs. Columns and bars represent means \pm SEM values, asterisks denote significant differences from control $(P<0.05)$. While \# from the ATX-II treated group. 
While selective inhibition of $\mathrm{I}_{\mathrm{NCX}}$ by either SEA0400 or ORM-10103 was found to be quite effective against the ATX-II induced increase in cellular $\mathrm{Ca}^{2+}$ load, it completely failed to suppress the significant lengthening of APD caused by ATX-II. Fig.5 A and $\mathbf{C}$, shows that when, SEA0400 and ORM-10103 were applied after ATX-II, eg. after ATX-II significantly lenghtened APD, they exerted no any modulation on the ATX-II -induced APD prolongation. Similarly, when the NCX inhibitors (Fig.5 B and D) were added as pretreatment, they were unable to prevent the ATX-II-induced APD prolongation. Thus, application of $1 \mu \mathrm{M}$ SEA0400 either prior to or following the ATX-II treatment had no effect on APD (Fig.5 A and B). Similarly to SEA0400, the more selective ORM-10103 was also ineffective against the ATX-II induced APD lengthening. Independently of the sequence of application it failed to prevent or even reduce significantly the APD lengthening effect of ATX-II (Fig.5 C and D).

\subsection{Global ischaemia}

\subsubsection{Comparison of the ischaemia-induced contracture's parameters}

Contracture, i.e. a sustained shortening and stiffening of the myocardium, can have several causes. In ischaemic myocardium, contracture develops by a rigor-type mechanism.

In Fig.6 we compare the time to the peak contracture occuring as a consequence of the ischemia. Time to peak contracture was significantly increased by the applied drugs compared to the control group, irrespective of whether they were applied alone or in combination.

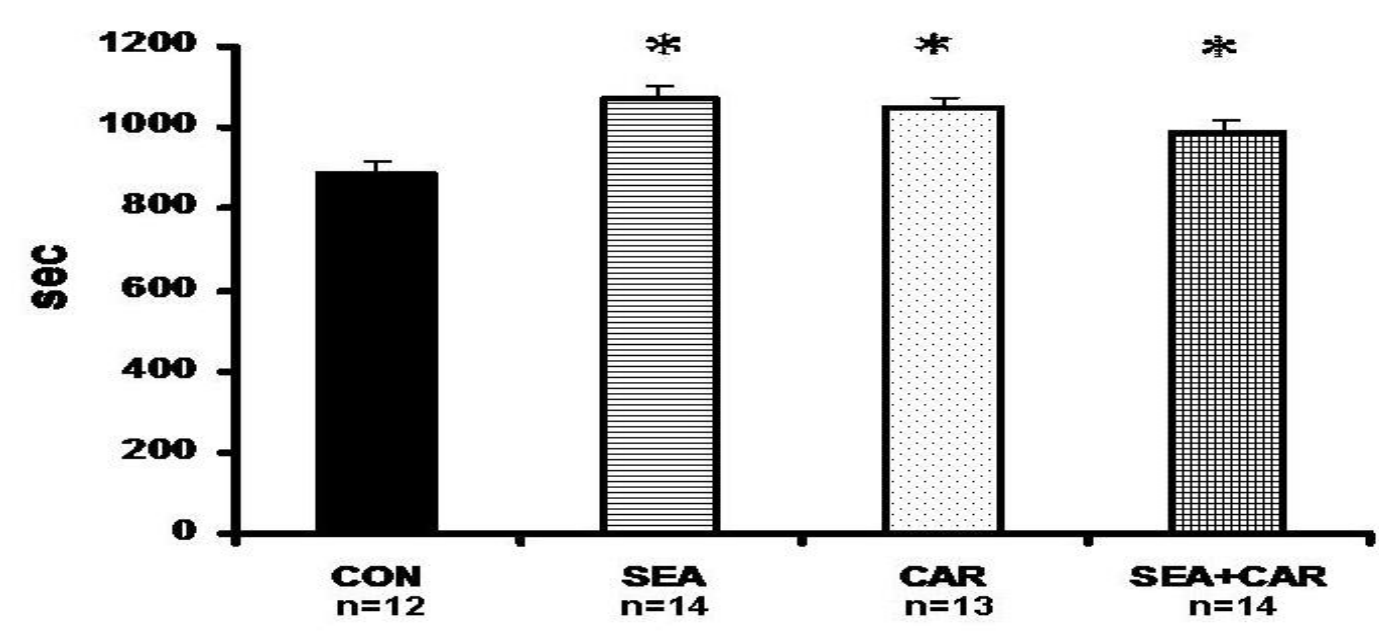

Fig. 6: The ondet of the maximal contracture was significantly delayed in the treated-groups.

Maximal extent of the ishaemic contracture is also an important parameter of the ischaemic damage of the myocardium. The amplitude of the contracture was significantly decreased by the drugs during the $25 \mathrm{~min}$ ischaemic period (Fig. 7). Again, they were equally effective alone and in combination. 


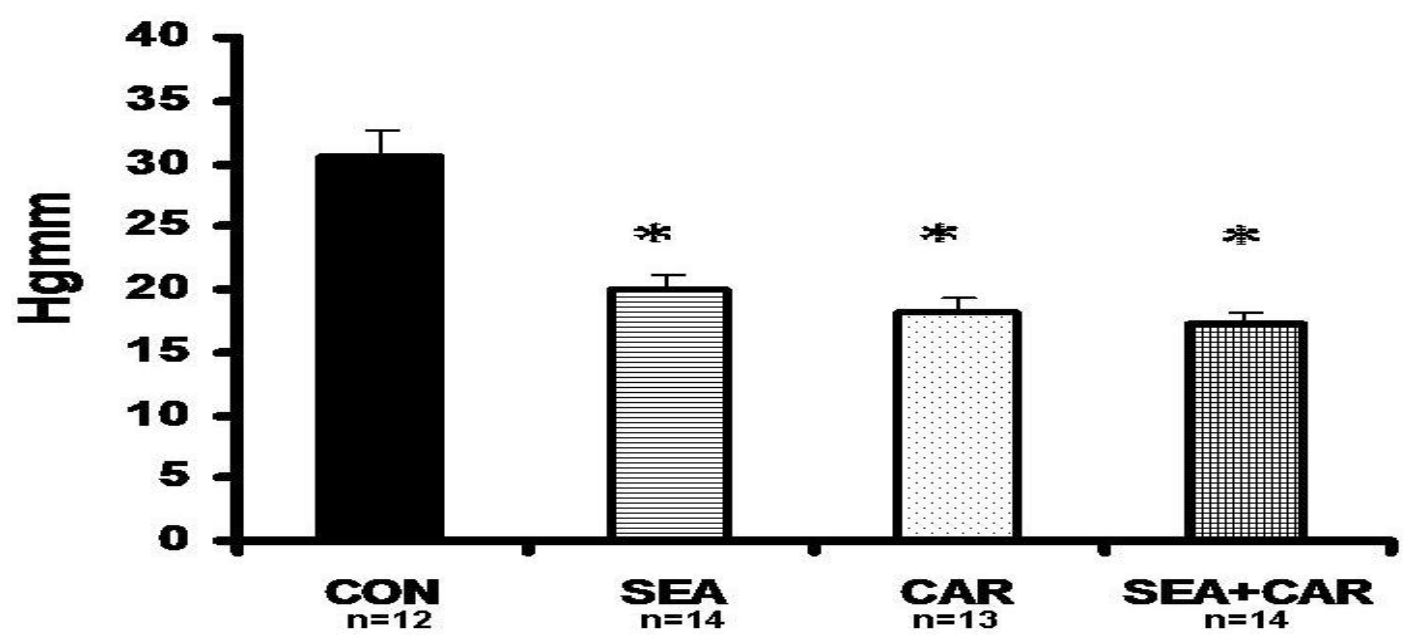

Fig. 7: Changes in the amplitudes of the contracture developed during the ischaemic period. Both SEA0400 and cariporide significantly decreased the maximal contracture.

We also analysed the contracture developed as a consequence of the reperfusion induced myocardial damage (Fig. 8). Again, SEA0400 and cariporide decreased the extent of the contracture significantly compared to the vehicle treated group. Interestingly, contrary to the expectations, combination of SEA0400 and cariporide did not show any increased protection neither in ischaemia nor in the reperfusion-induced contracture.

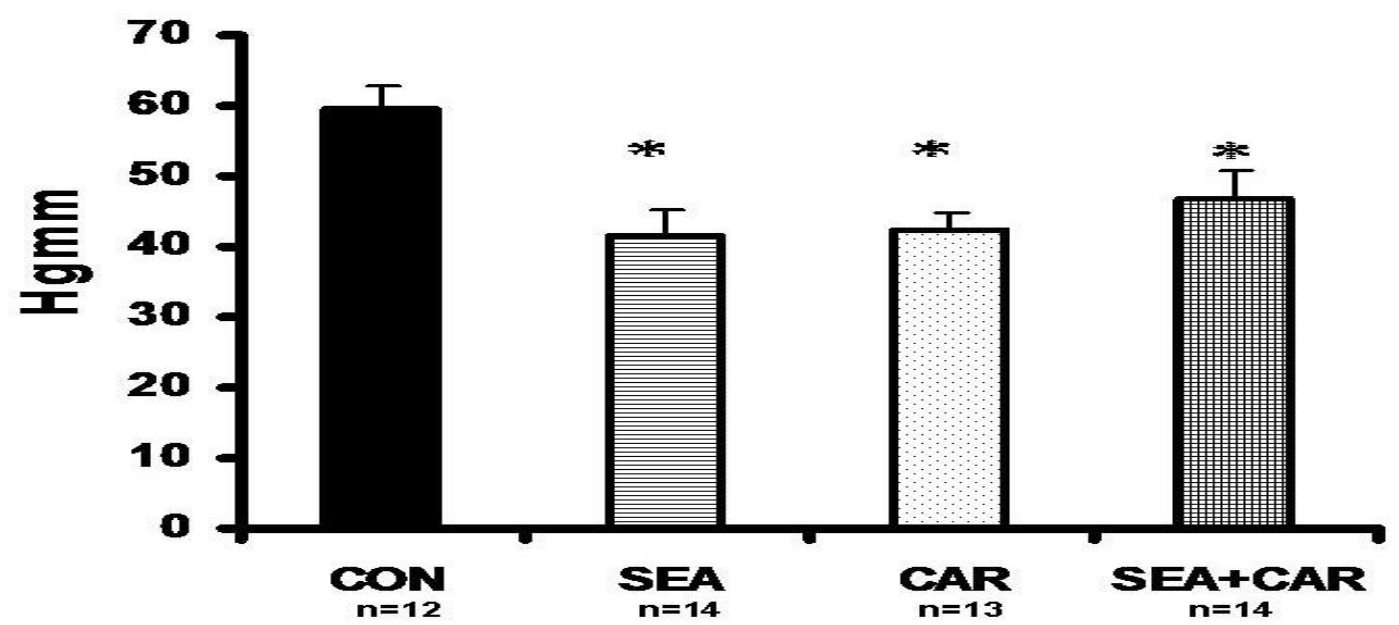

Fig. 8:The contracture developed upon reperfusion of the myocardium. Both drugs, either alone or in combination significantly reduced the reperfusion-induced contracture. 


\subsection{2 . Measurements of functional recovery}

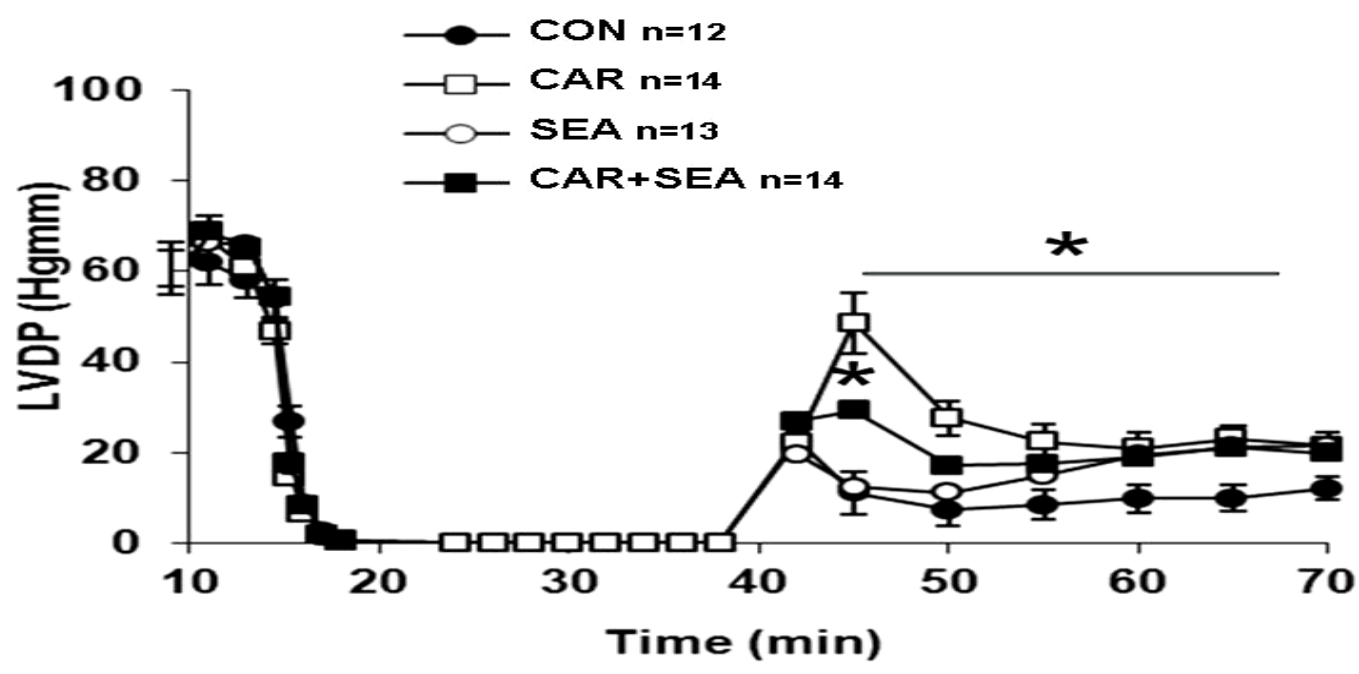

Fig. 9: Changes in the left ventricular developed pressure in the reperfusion period.

The end-diastolic pressure is the main indicator of the ability of the heart to relax at the end of cardiac cycle. Thus, it is an important parameter for mapping how the myocardial cells damaged and developed the contracture under ischaemic conditions and also during the first minutes of the reperfusion. Functional impairment associated with ischaemia /reperfusion was also assessed by measurements of left ventricular developed pressure (LVDP) and changes in end -diastolic pressure (LVEDP) as described previously [42]. In Fig. 9 and 10 show the average time courses of LVDP and LVEDP of the control and different treatment groups are depicted. Mean values were sampled from the baseline, ischemic and reperfusion period.

In the control group effective mechanical activity (LVDP $>8 \mathrm{Hgmm}$ ) recovered only in $25 \%$ of the hearts - during the first 10 minutes of reperfusion. This value was significantly improved in the treatment groups (Fig 9). The rate of effective recovery was 55,5\% in the hearts treated with SEA0400, while cariporide increased it to $87,5 \%$. The recovery rate was $68,7 \%$ in the heart with combined SEA0400 and cariporide treatment. The reperfusion caused further damage in the ventricular functions, indicated by the elevated end-diastolic pressure and the decreased developed pressure. Among the inhibitors only cariporide was able to demonstrate a significant protection regarding LVDP. Interestingly, the combinated treatment (SEA0400+ CAR) did not provide a greater protection (Fig.9).

In both treated groups the end-diastolic pressure was significantly lower than in the control group. This cardioprotective effect was maintained during the whole reperfusion (Fig. 10). 


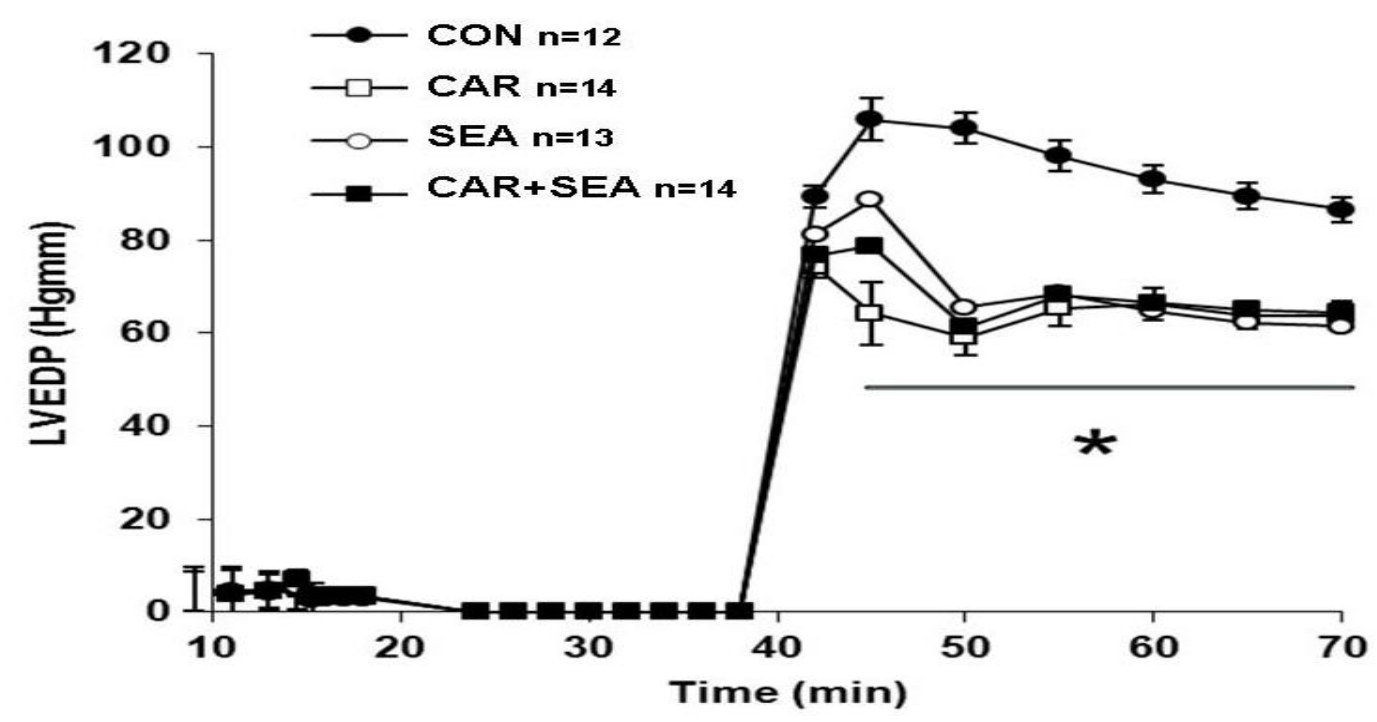

Fig 10: The ischaemia - induced functional impairment in the left ventricular end -diastolic pressure. In the reperfusion period all the treated group showed a significant decrease in LVEDP, indicating similar level of protection compared to the control group.

\subsection{Regional ischaemia}

\subsubsection{Haemodynamic parameters}

Major haemodynamic parameters (CF, HR, LVSP, LVEDP, DP, and $\left.\pm d P / d t_{\max }\right)$, measured or calculated for all six experimental groups, in all four phases (control, pre-treatment, ischaemia, and reperfusion) are summarised in Table 1. Pre-treatment of the hearts with the vehicle (DMSO), an NCX or NHE inhibitor, or their combination had no apparent effect on any of the haemodynamic parameters. Compared to control values, however, ischaemia induced a large, significant decrease in CF, LVSP, DP and $\pm \mathrm{dP} / \mathrm{dt}_{\max }$, while the HR and LVEDP were practically unchanged. During the reperfusion phase, the CF recovered, while the LVSP, DP and $\pm \mathrm{dP} / \mathrm{dt}_{\max }$ remained significantly lower than in the control state. In contrast, LVEDP became significantly enhanced in all experimental groups. Nonetheless, is should be emphasised that the $\mathbf{n}$ numbers for the reperfusion data are substantially lower than for all other states. Importantly and interestingly, using one-way ANOVA, no significant intergroup differences could be found in values obtained from the control and test groups during any experiment phase. 


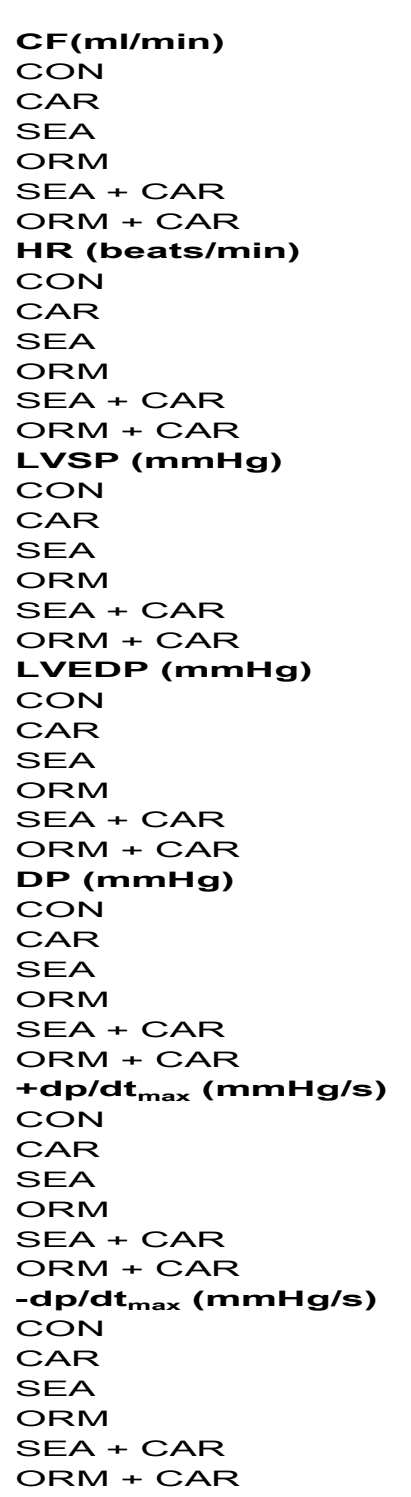

\begin{tabular}{|c|c|c|c|c|}
\hline Control & Pretreatment & Ischemia & & Reperfusion \\
\hline $17.5 \pm 0.9$ & $17.1 \pm 1.0$ & $9.3 \pm 0.9$ & $\star$ & $15.6 \pm 1.4$ \\
\hline $19.1 \pm 1.5$ & $18.4 \pm 1.5$ & $13.2 \pm 1.8$ & $\star$ & $16.7 \pm 2.3$ \\
\hline $16.6 \pm 0.8$ & $16.4 \pm 1.1$ & $10.0 \pm 1.4$ & $\star$ & $14.1 \pm 1.3$ \\
\hline 16.8士1.07 & $17.3 \pm 1.1$ & $9.8 \pm 0.9$ & $\star$ & $15.5 \pm 1.5$ \\
\hline $16.8 \pm 1.4$ & $15.6 \pm 1.3$ & $9.4 \pm 1.1$ & $\star$ & $13.5 \pm 1.6$ \\
\hline $20.5 \pm 0.9$ & 20.9士1.0 & $11.0 \pm 1.3$ & $\star$ & $16.7 \pm 1.3$ \\
\hline $313 \pm 11$ & $295 \pm 10$ & $280 \pm 12$ & $\star$ & $277 \pm 12$ \\
\hline 325士113 & 320士11 & $310 \pm 12$ & & $280 \pm 14$ \\
\hline $297 \pm 10$ & $301 \pm 11$ & $294 \pm 12$ & & $281 \pm 20$ \\
\hline $311 \pm 12$ & $308 \pm 12$ & $302 \pm 12$ & & $303 \pm 19$ \\
\hline 303士15 & $288 \pm 21$ & $287 \pm 18$ & & $308 \pm 28$ \\
\hline $343 \pm 9$ & $310 \pm 13$ & $309 \pm 11$ & & $279 \pm 7$ \\
\hline $101 \pm 3$ & $102 \pm 3$ & $55 \pm 6$ & & $73 \pm 7$ \\
\hline $101 \pm 3$ & $98 \pm 2$ & $55 \pm 7$ & & $88 \pm 2$ \\
\hline $92 \pm 3$ & $90 \pm 4$ & $47 \pm 6$ & & $74 \pm 5$ \\
\hline $96 \pm \mathbf{3}$ & $94 \pm 7$ & $37 \pm 5$ & & $61 \pm 16$ \\
\hline $92 \pm 4$ & $94 \pm 5$ & $47 \pm 6$ & & $55 \pm 12$ \\
\hline $95 \pm 3$ & $98 \pm 3$ & $39 \pm 4$ & & $90 \pm 7$ \\
\hline $5.0 \pm 1.4$ & $5.0 \pm 1.6$ & $5.6 \pm 1.6$ & $\star$ & $18.4 \pm 4.8$ \\
\hline $7.4 \pm 1.5$ & $7.8 \pm 1.5$ & 8.1士1.2 & $\star$ & $15 \pm 3.9$ \\
\hline $5.9 \pm 0.7$ & $5.4 \pm 1.1$ & $6.3 \pm 1.3$ & $\star$ & $11.2 \pm 6.3$ \\
\hline $5.8 \pm 0.5$ & $4.3 \pm 0.8$ & $5.3 \pm 0.9$ & $\star$ & $5.1 \pm 0.34$ \\
\hline 5. $1 \pm 1.1$ & $7.4 \pm 2.3$ & $7.4 \pm 2.5$ & $\star$ & $15.7 \pm 7.4$ \\
\hline $5.5 \pm 0.9$ & $4.3 \pm 0.9$ & $4 \pm 0.8$ & $\star$ & $21.1 \pm 8.1$ \\
\hline $96 \pm 3$ & $97 \pm 3$ & $55 \pm 5$ & $\star$ & $55 \pm 6$ \\
\hline $93 \pm 4$ & $90 \pm 4$ & $47 \pm 7$ & $\star$ & $72 \pm 6$ \\
\hline $86 \pm 3$ & $85 \pm 5$ & $41 \pm 6$ & $\star$ & $63 \pm 8$ \\
\hline $90 \pm \mathbf{3}$ & $90 \pm 6$ & $32 \pm 4$ & $\star$ & $61 \pm 12$ \\
\hline $85 \pm 4$ & $86 \pm 6$ & $39 \pm 6$ & $\star$ & $39 \pm 11$ \\
\hline $89 \pm 3$ & $94 \pm 3$ & $35 \pm 4$ & $\star$ & $69 \pm 8$ \\
\hline $2678 \pm 124$ & $2721 \pm 140$ & $1510 \pm 147$ & $\star$ & $1587 \pm 155$ \\
\hline $2388 \pm 199$ & $2422 \pm 186$ & $1344 \pm 181$ & $\star$ & $2222 \pm 238$ \\
\hline $2315 \pm 176$ & $2361 \pm 209$ & $1238 \pm 138$ & $\star$ & $1583 \pm 186$ \\
\hline $2691 \pm 172$ & $2791 \pm 259$ & $1166 \pm 113$ & $\star$ & $1714 \pm 295$ \\
\hline $2666 \pm 193$ & $2733 \pm 170$ & $1533 \pm 170$ & $\star$ & $1600 \pm 358$ \\
\hline $2191 \pm 96$ & $2208 \pm 100$ & $975 \pm 88$ & $\star$ & $1640 \pm 208$ \\
\hline$-1942 \pm 70$ & $-1963 \pm 75$ & $-994 \pm 94$ & $\star$ & $-1150 \pm 125$ \\
\hline$-1722 \pm 151$ & $-1733 \pm 113$ & $-966 \pm 148$ & $\star$ & $-1422 \pm 98$ \\
\hline$-1784 \pm 93$ & $-1723 \pm 127$ & $-938 \pm 104$ & $\star$ & $-1266 \pm 120$ \\
\hline$-2108 \pm 113$ & $-2175 \pm 171$ & $-891 \pm 79$ & $\star$ & $-1400 \pm 296$ \\
\hline$-1822 \pm 111$ & $-1822 \pm 145$ & $-911 \pm 116$ & $\star$ & $-1166 \pm 322$ \\
\hline$-1825 \pm 93$ & $-1891 \pm 96$ & $-808 \pm 67$ & $\star$ & $-1480 \pm 131$ \\
\hline
\end{tabular}

Table 1. Major hemodynamic variables (CF coronary flow; HR heart rate; LVSP left ventricular systolic pressure; LVEDP left ventricular end-diastolic pressure; DP developed pressure) The numbers of the control,the pretreatment and the ischemia experiments: $C O N n=19$; $C A R n=9$; SEA $n=13$; ORM $n=12$ SEA+CAR $n=12$; ORM+CAR $n=13$ The numbers of the reperfusion experiments: $C O N n=8 ; C A R n=9 ;$; $S E A n=6$ ORM $n=7 ; S E A+C A R \quad n=6 ; O R M+C A R n=5$. $*, \S P<0.05$ compared to the baseline control period (Repeated measure ANOVA), with the indicated sample size for the reperfusion period (see text for the details).

\subsubsection{Arrhythmia diagrams}

The raw results of the arrhythmia analysis for all experimental groups are summarised in the graphical arrhythmia diagram shown in Fig. 11. Following a relatively short (10 min) period of regional ischaemia, the most common type of reperfusion-induced arrhythmias evoked in control (CON) rat hearts (treated solely with the vehicle, DMSO) was VF. The antiarrhythmic efficacy of the selective NHE inhibitor, cariporide, at least in this simple model, was excellent. Compared to the very high incidence of VFs present in the control group, cariporide treatment drastically reduced the incidence and even more the duration of reperfusion-induced arrhythmias. The antiarrhythmic efficacy of the two NCX inhibitors, SEA0400 and ORM-10103, either alone or in 
combination with cariporide, can hardly be quantitatively estimated by simply looking at the arrhythmia diagram. Nonetheless, it is obvious that none of these treatments has been as effective as cariporide treatment alone. In order to better reveal the relatively moderate but possibly important differences between various treatments, especially for the two types of less severe reperfusion induced arrhythmias (ES and VT), a more detailed, quantitative analysis has been carried out (see below).

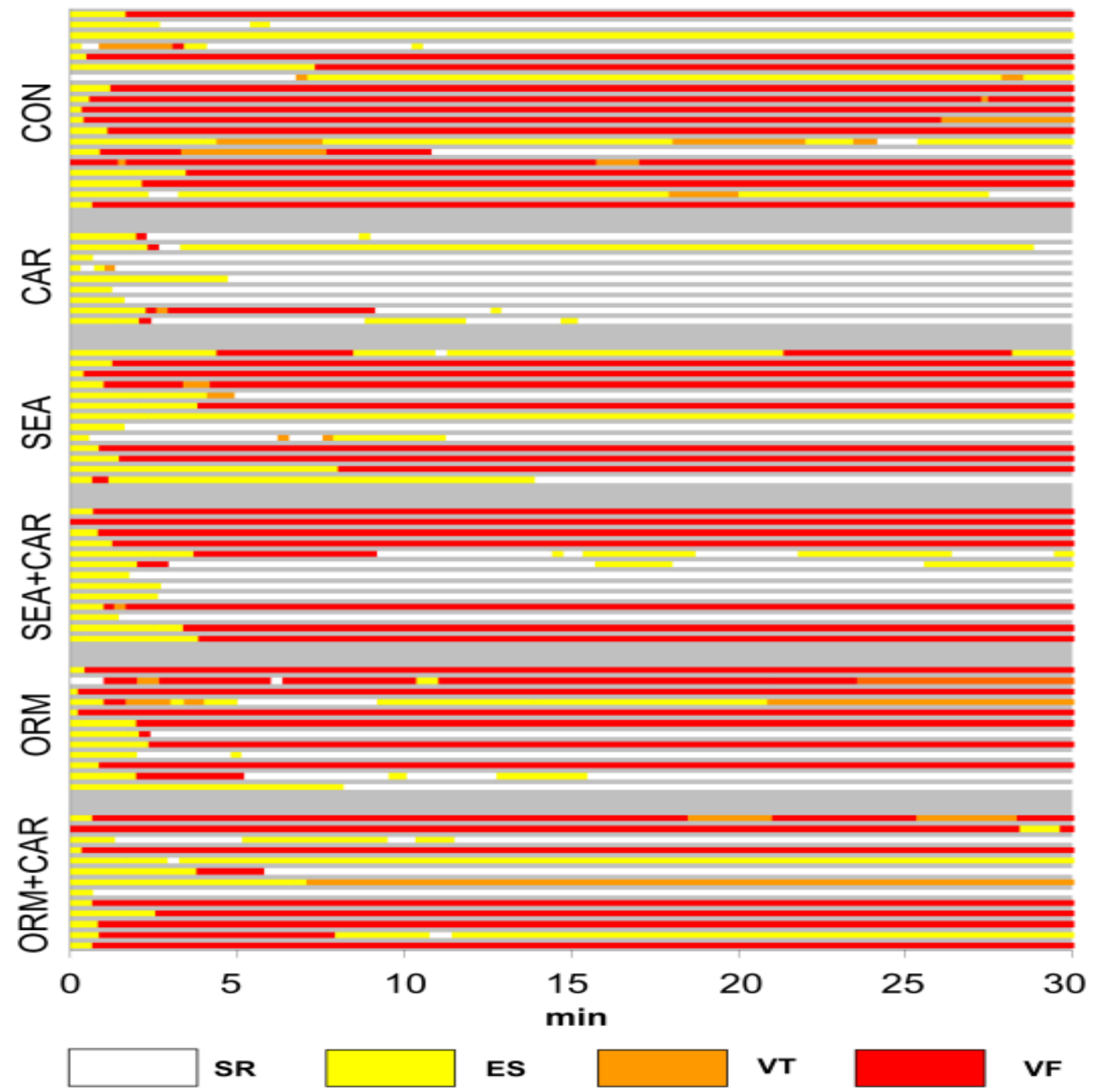

Fig. 11: Integrated arrhythmia diagram calculated from all hearts. $X$ axis: reperfusion time; $Y$ axis: arrhythmia diagrams of 78 individual hearts. The hearts were divided into 6 groups: $\mathrm{CON}$ ( $n=19)$ : control (only vehicle: 0.01mM DMSO); CAR (n=9): $5 \mu$ M cariporide, SEA (n=12): $1 \mu M$ SEA0400; ORM (n=12): $1 \mu M$ ORM-10103; SEA+CAR $(n=13): 1 \mu M$ SEA0400 + $5 \mu$ M cariporide; ORM+CAR $(n=13): 1 \mu M$ ORM-10103 + $5 \mu$ M cariporide. Each of the horizontal lines represents a single heart. Time periods with the various arrhythmia stages are shown in colour: white: regular sinus rhythm (SR); yellow: multiple extrasystoles (ES); brown: ventricular tachycardia (VT) and red: ventricular fibrillation $(\boldsymbol{V F})$ 


\subsubsection{Quantitative analysis of the incidence and duration during reperfusion of the sinus rhythm (SR) and the three major types of arrhythmia (ES, VT and VF)}

Average durations of periods with regular sinus rhythm $\left(\mathrm{SR}_{\mathrm{D}}\right)$ during the $\mathbf{3 0}$ min reperfusion phase are summarised in Fig.12. The control value $(5.26 \pm 2.14 \mathrm{~min})$ was calculated from the unified pool of control rats collected throughout the study. All further differences were evaluated relative to this control value.

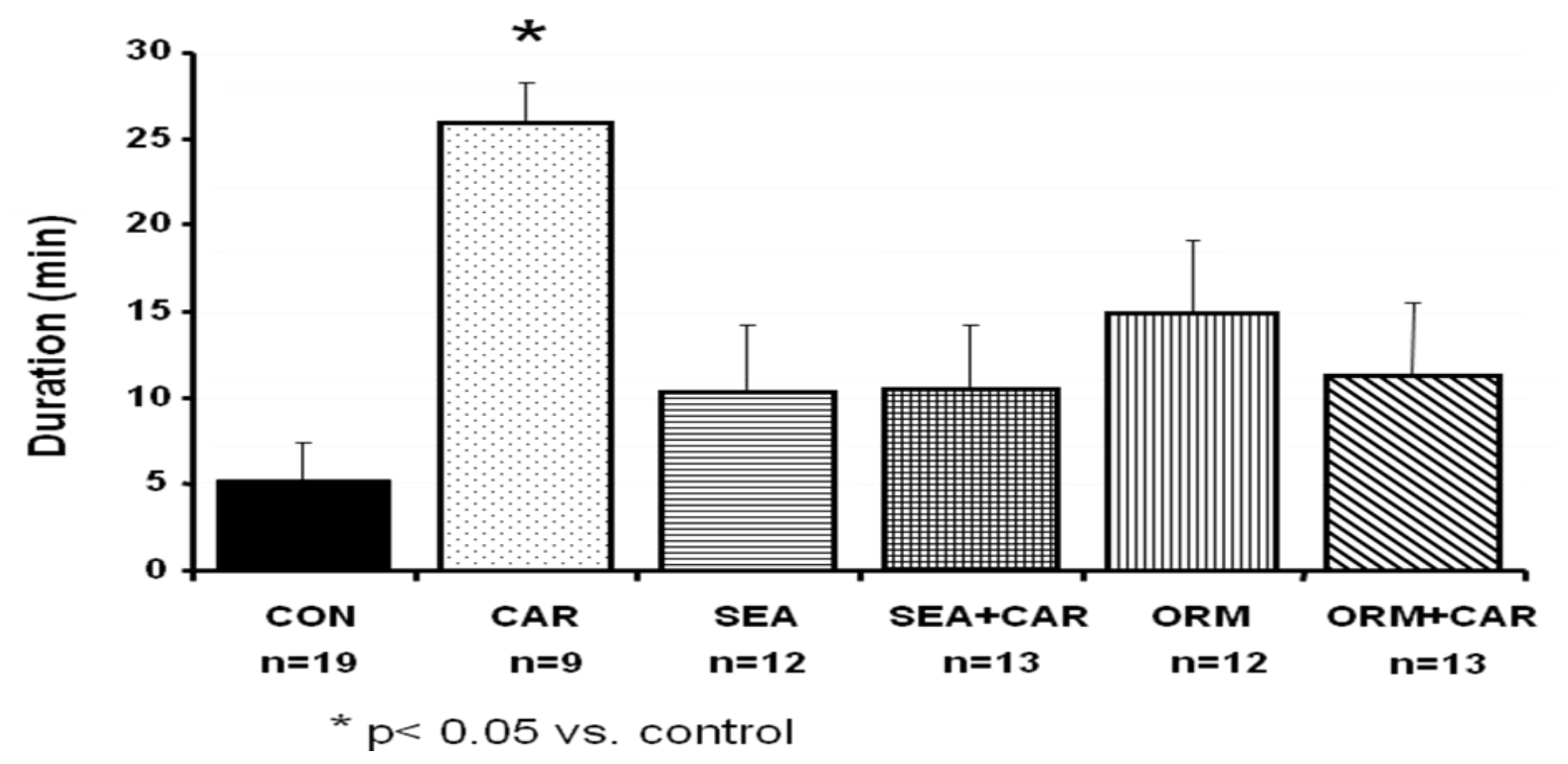

Fig. 12: Total duration of periods with regular sinus rhythm $\left(S R_{D}:\right.$ min) during the 30 min reperfusion phase in all groups. The efficacy of individual inhibitors and inhibitor combinations has been evaluated against the control hearts. $*=p<0.05$, compared to the control group.

Cariporide, when used alone, significantly increased the overall duration of the SR periods during reperfusion (25.8 $\pm 2.4 \mathrm{~min})$. All other pharmacological treatments were apparently beneficial, but neither was found to be significant. While in three of the four groups with an NCX inhibitor, the effect was similar $(10.26 \pm 3.89 ; 10.57 \pm 3.61$ and $11.25 \pm 4.16$ min for SEA, SEA+CAR and ORM+CAR groups, respectively), further to cariporide, the second largest improvement was achieved in the group treated with ORM alone (14.86 $\pm 4.24 \mathrm{~min})$. 

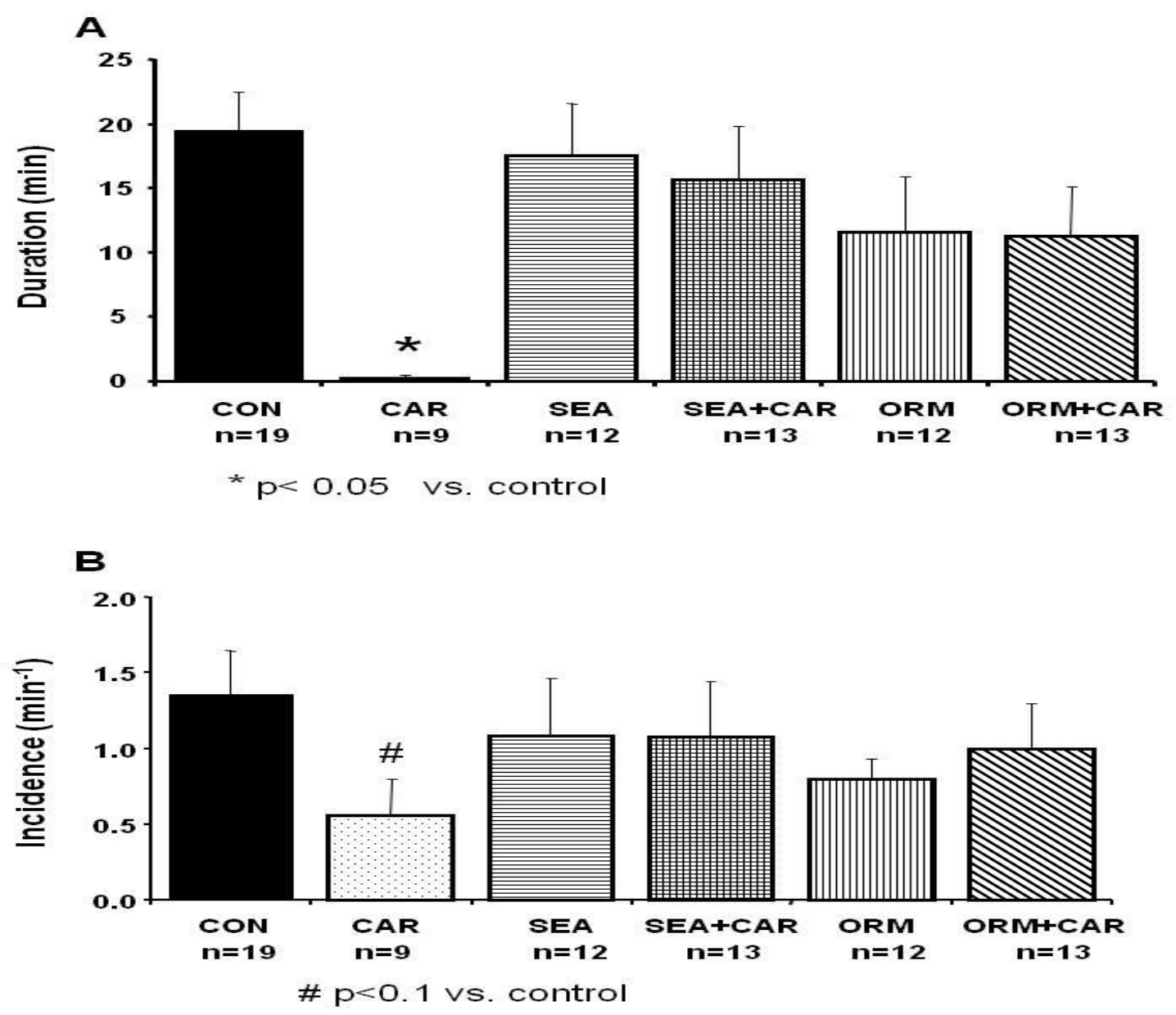

Fig. 13:Total duration $\left(V F_{D}:\right.$ min) and incidence $\left(V F_{I}: \min ^{-1}\right)$ of periods with ventricular fibrillation $(V F)$ during the 30 min reperfusion period. Two levels of significance, has been calculated: $*=p<0.05$, \# $p<0.1$, compared to the control group.

The incidence and average duration of the VF periods, calculated for all groups, are shown in Fig. 13. In control hearts, both the average duration $\left(\mathrm{VF}_{\mathrm{D}}\right)(19.39 \pm 3.01 \mathrm{~min})$ and incidence $\left(\mathrm{VF}_{\mathrm{I}}\right)$ $\left(1.35 \pm 0.24 \mathrm{~min}^{-1}\right)$ of VF was high. Furthermore, 11 out of the 19 hearts utilised in the control group were in the state of sustained fibrillation at the end of the reperfusion phase.

Compared to the control hearts, cariporide, if used alone, significantly decreased the incidence $\left(0.55 \pm 0.24 \mathrm{~min}^{-1}\right)$ and particularly the duration $(0.25 \pm 0.21 \mathrm{~min})$ of the fibrillatory periods. At the end of reperfusion in this group, none of the 9 hearts was fibrillating. Unlike cariporide, however, the NCX inhibitors, although exerting a moderate beneficial effect, were apparently unable to significantly reduce the incidence or duration of the VF periods. Neither SEA0400 (I: $1.08 \pm 0.37$ $\min ^{-1}$; D: $17.86 \pm 4.07 \mathrm{~min}$ ) nor ORM-10103 (I: $0.80 \pm 0.13 \mathrm{~min}^{-1}$; D: $11.57 \pm 4.29 \mathrm{~min}$ ) could markedly decrease the incidence or average duration of the VF periods. From this aspect, the overall anti-VF efficacy of ORM-10103 was slightly more promising. While no apparent 
difference could be observed in the number of hearts with sustained fibrillation (6/12 (ORM10103) compared to 7/13 (SEA0400), the duration of the VF periods was moderately lower in the ORM-10103-treated group compared to the SEA0400-treated group.

Surprisingly, if cariporide was administered together with an NCX inhibitor, it failed to improve the moderate anti-VF protection reached by application of the NCX inhibitor alone (SEA+CAR, I: 1.07 $\pm 0.36 \mathrm{~min}^{-1}$; D: $15.67 \pm 4.10 \mathrm{~min}$; ORM+CAR, I: $1.00 \pm 0.29 \mathrm{~min}^{-1}$; D: $\left.11.25 \pm 3.85 \mathrm{~min}\right)$. These results suggest that instead of providing enhanced cardioprotection, the simultaneous application of inhibitors of the two transporters results in a "loss of action" effect of cariporide.
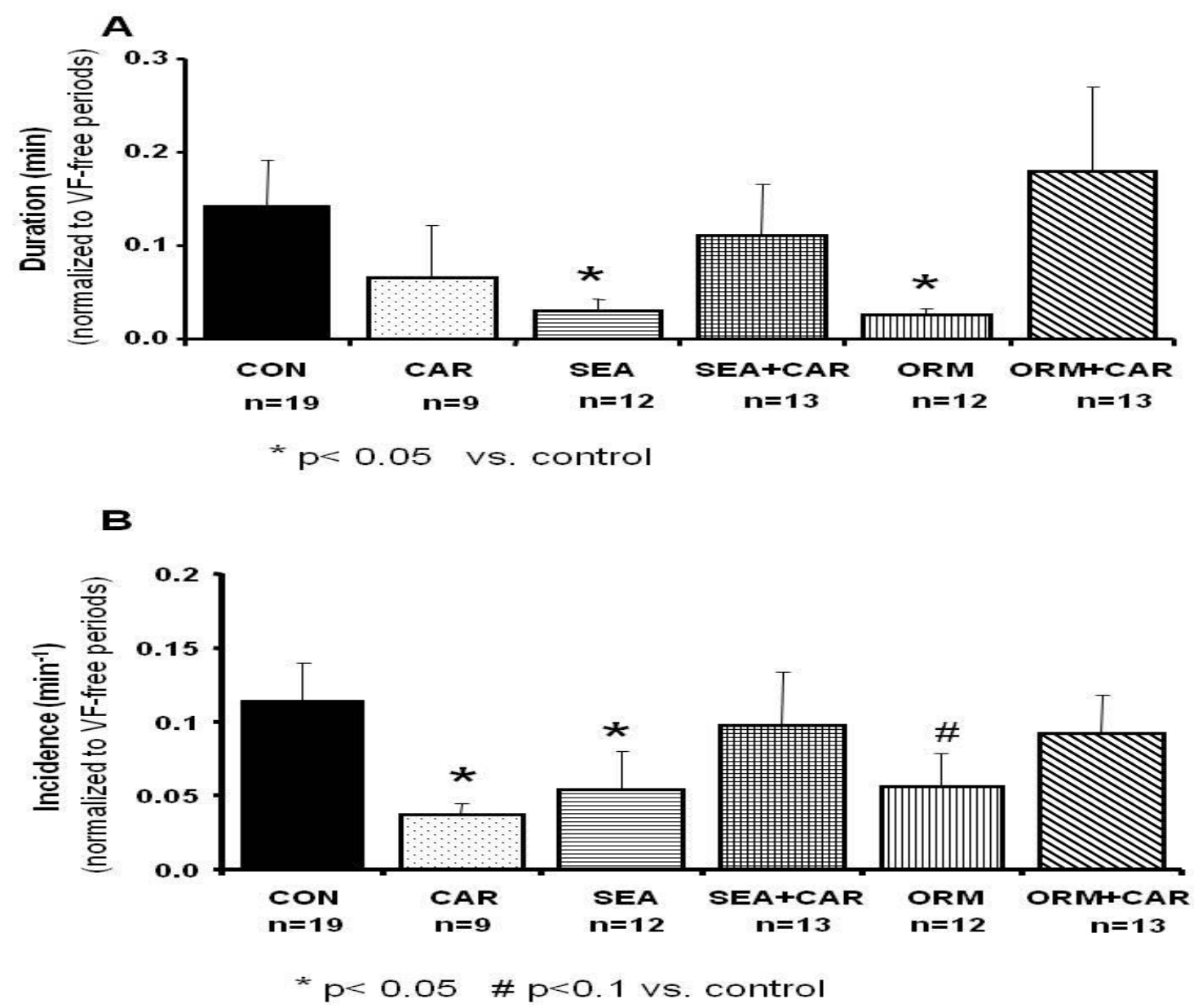

Fig.14: Relative duration (ES $S_{D}$ : $\left.\min \right)$ and incidence $\left(E S_{I}:\right.$ min $\left.^{-1}\right)$ of episodes with multiple extrasystoles (ESs) during the reperfusion phase. In order to better characterise the sensitivity of the heart to reperfusion-induced VT, the raw duration ( $\mathrm{min}$ ) and incidence $\left(\mathrm{min}^{-1}\right)$ values for each heart were normalised to the total duration of the VF-free periods obtained for the same heart (see the METHODS section for details). Two levels of significance were calculated: * = $p<0.05$, \# $=p<0.1$, compared to the control group.

The incidence and duration values calculated for periods with multiple extrasystoles (ESs) are shown in Fig. 14. As explained in METHODS, in order to more realistically compare the incidence and duration of the ES (and VT) intervals during the reperfusion phase, the calculated raw values 
for each heart were normalised to the duration of the VF-free periods. With this step, these variables became independent of the incidence and duration of the VF periods. In control hearts, both the incidence $\left(\mathrm{ES}_{\mathrm{I}}\right)\left(0.11 \pm 0.02 \mathrm{~min}^{-1}\right)$ and duration $\left(\mathrm{ES}_{\mathrm{D}}\right)(0.14 \pm 0.04 \mathrm{~min})$ of the $\mathrm{ES}$ episodes was high. Cariporide, if applied alone, significantly decreased the incidence $\left(0.03 \pm 0.007 \mathrm{~min}^{-1}\right)$ and markedly reduced the average duration $(0.066 \pm 0.05 \mathrm{~min})$ of these episodes. The incidence and especially the duration of the ES episodes were also significantly reduced by both NCX inhibitors (ESI: SEA: 0.05 $\pm 0.02 \mathrm{~min}^{-1}$; ORM: $0.05 \pm 0.02 \mathrm{~min}^{-1}$; $\mathrm{ES}_{\mathrm{D}}$ : SEA: $0.02 \pm 0.01 \mathrm{~min}$; ORM: $\left.0.02 \pm 0.007 \mathrm{~min}^{-1}\right)$. As expected, in the latter case, the antiarrhythmic efficacy of the NCX inhibitors was apparently greater than that of NHE inhibition. In contrast, if applied in combination with an NCX inhibitor, cariporide not only failed to improve, but virtually eliminated the beneficial effect of NCX inhibition on the duration and incidence of the ES episodes (SEA+CAR: $0.11 \pm 0.05 \mathrm{~min}$ and $0.09 \pm 0.03 \mathrm{~min}^{-1}$; ORM+CAR: $0.17 \pm 0.09 \mathrm{~min}$ and $0.09 \pm 0.02 \mathrm{~min}^{-}$ ${ }^{1}$, respectively).

Normalised incidence and average duration values obtained for the ventricular tachycardia (VT) periods generated during reperfusion are summarised in Fig. 15. As in other arrhythmia types, in control hearts, both the incidence $\left(0.17 \pm 0.04 \mathrm{~min}^{-1}\right)$ and average duration $(0.14 \pm 0.05 \mathrm{~min})$ of the periods with VT were high. Cariporide treatment provided the most effective anti-VT protection by dramatically decreasing both the incidence and duration of the post-ischaemic VT periods (VT: $0.01 \pm 0.002 \mathrm{~min}^{-1}$; $\mathrm{VT}_{\mathrm{D}}$ : $0.005 \pm 0.001 \mathrm{~min}$ ). However, unlike the ES episodes, while both NCX inhibitors exerted a moderate beneficial effect, neither could significantly reduce the incidence or duration of the VT periods (SEA: $0.16 \pm 0.04 \mathrm{~min}^{-1}$ and $0.13 \pm 0.05 \mathrm{~min}$; ORM: $0.10 \pm 0.03 \mathrm{~min}^{-1}$ and $0.09 \pm 0.07 \mathrm{~min}$, respectively). Furthermore, the simultaneous application of cariporide and an NCX inhibitor resulted in the almost complete abolishment of the protection provided by cariporide treatment alone (SEA+CAR: $0.13 \pm 0.06 \mathrm{~min}^{-1}$ and $0.05 \pm 0.05 \mathrm{~min}$; ORM+CAR: $0.09 \pm 0.07 \mathrm{~min}^{-1}$ and $0.10 \pm 0.05 \mathrm{~min}$ ). 

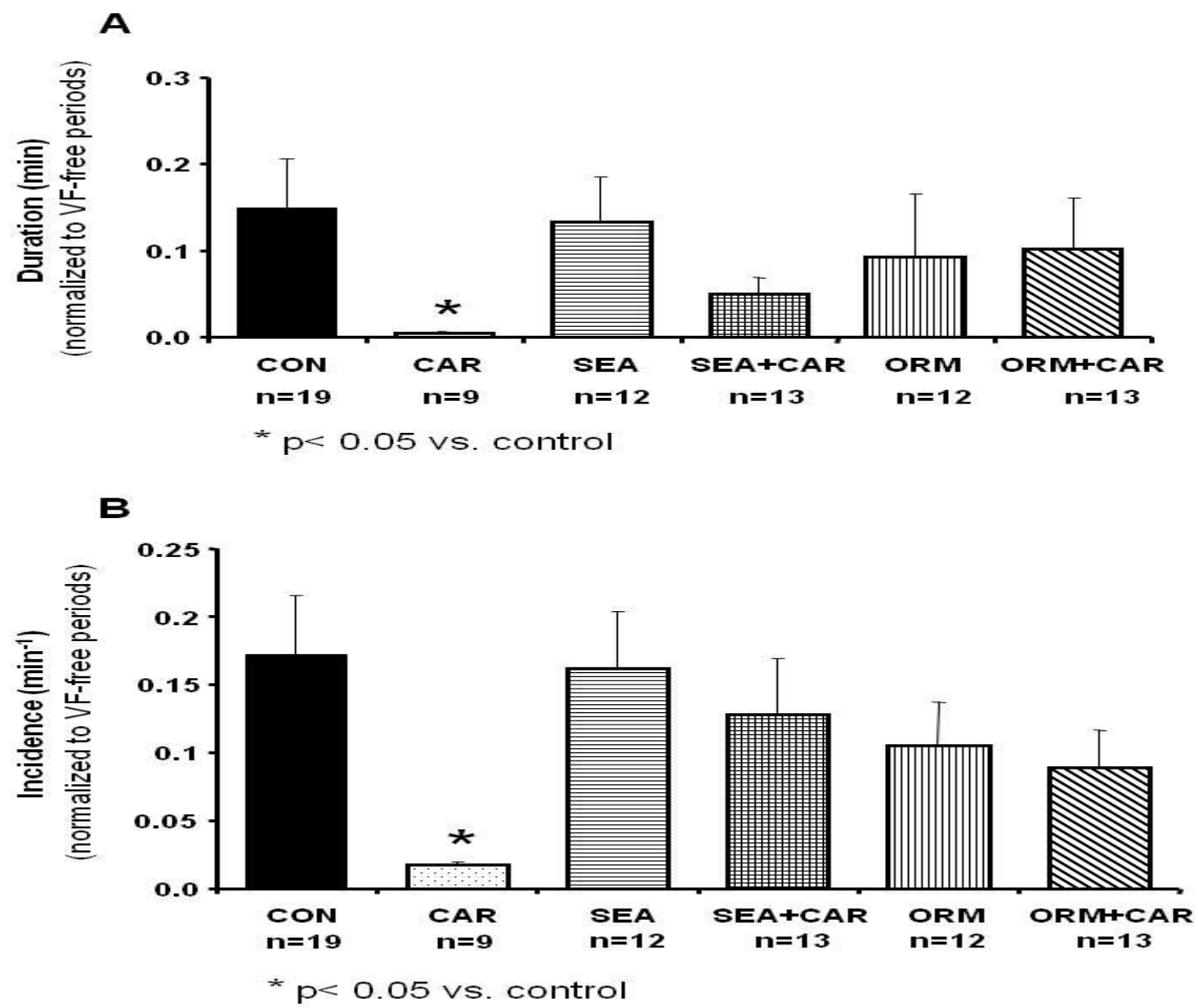

Fig. 15: Relative duration (VT $:$ min) and incidence $\left(V T_{I}:\right.$ min $\left.^{-1}\right)$ of episodes with ventricular tachycardia $(V T)$ during the reperfusion phase. Like in Fig. 6, the raw duration (min) and incidence $\left(\mathrm{min}^{-1}\right)$ values for each heart were normalised to the total duration of the VF-free periods obtained for the same heart; $*=p<0.05$, compared to the control group.

\section{DISCUSSION}

\subsection{Failure of selective NCX inhibition to modulate ventricular AP}

Late $\mathrm{I}_{\mathrm{Na}}$ is a small inward current that reduces repolarization reserve and prolongs the duration of the AP in cardiac myocytes. Physiological roles for late $\mathrm{I}_{\mathrm{Na}}$ include the contribution to the $\mathrm{Na}^{+}$ loading, and thus the maintenance of the normal inotropic state, and the AP prolongation which may increase the effective refractory period and decrease reentry. These theoretical possiblities, however, have not been adequately investigated yet. The amplitude of late $\mathrm{I}_{\mathrm{Na}}$ is increased in many pathological conditions, where it contributes to atrial and ventricular arrhythmogenesis. An increase of late $\mathrm{I}_{\mathrm{Na}}$ due to acquired or inherited $\mathrm{Na}^{+}$channelopathies abnormally prolongs repolarization and increases the influx of $\mathrm{Na}^{+}$, and via $\mathrm{NCX}, \mathrm{Ca}^{2+}$ into the cell. Late $\mathrm{I}_{\mathrm{Na}}$ and $\mathrm{NCX}$ mediated $\mathrm{Ca}^{2+}$ loading increase diastolic force production. AP prolongation and $\mathrm{Na}^{+} / \mathrm{Ca}^{2+}$ loading cause CaMKII activation and electrical instability. Enhancement of late $I_{\mathrm{Na}}$ may lead to 
automaticity, EADs and DADs, and $\mathrm{Ca}^{2+}$ and $\mathrm{AP}$ alternans that facilitate arrhythmias by triggered and reentrant mechanisms. Drugs that reduce late $\mathrm{I}_{\mathrm{Na}}$ have been shown to reduce EADs, DADs, $\mathrm{Ca}^{2+}$ handling defects, and arrhythmias. Interactions between late $\mathrm{I}_{\mathrm{Na}}$, CaMKII, RyR2, and oxidative stress have also been demonstrated, and their potential pathological roles in ischaemic heart disease, heart failure, and arrhythmias are subjects of current and future investigation.

Selective NCX inhibition failed to modulate APD - neither as pretreatment nor following the exposure to ATX-II (Fig.5.). The NCX inhibition induced uncoupling between $\mathrm{I}_{\mathrm{NaL}}$ and $\left[\mathrm{Ca}^{2+}\right]_{\mathrm{i}}$ handling may also be effective under these conditions, however, it seems to exert only a minor effect on APD. Furthermore, considering the similar ineffectiveness of these inhibitors on APD we concluded that ORM-10103 should have negligible effect on increased APD dispersion. This observation contradicts to the results of Milberg et al. [43] but supports the findings of Farkas et al. [44] The reason of the discrepancy between our present findings and those of Milberg et al, is unclear. It can be different experimental condition, methods of investigation, species differences. Importantly, the delicate nature of SEA0400 inhibition on $\mathrm{I}_{\mathrm{Ca}}$ and NCX may play a role int he opposing resuts and needs further experiments.

The reason for the lack of effect on APD seems to be rather complex. Theoretically, the lengthening of APD following the enhancement of $\mathrm{I}_{\mathrm{NaL}}$ may have two sources: (1) a direct, i.e. the effect of the increased $\mathrm{I}_{\mathrm{NaL}}$ on APD, and (2) an indirect, i.e. the role of $\mathrm{I}_{\mathrm{NCX}}$ in defining actual APD. We can assume that inhibition of $\mathrm{NCX}$ has no direct effect on $\mathrm{I}_{\mathrm{NaL}}$ which may partially explain its failure to counteract APD prolongation. On the other hand, direct estimation of $\mathrm{I}_{\mathrm{NCX}}$ kinetics during an AP is complicated following the application of ATX-II.

Inhibition of NCX, however, reduced $\left[\mathrm{Ca}^{2+}\right]_{\mathrm{i}}$ without an apparent effect on APD. It is possible that a primary reduction in CaT via negative feed-back prolongs ICa inactivation and subsequently lengthens APD. Therefore, if NCX inhibition had any direct effect on APD (i.e. $\mathrm{I}_{\mathrm{NCX}}$ mediated abbreviation), it could be largely reduced by this indirect mechanism (i.e. $\mathrm{I}_{\mathrm{CaL}}$ mediated prolongation). NCX inhibition, following the $\mathrm{I}_{\mathrm{NaL}}$ induced rise in $\left[\mathrm{Ca}^{2+}\right]_{i}$, may have two parallel, but opposite effects on APD: directly, it may abbreviate APD via inhibition of $\mathrm{IN}_{\mathrm{CX}}$, but indirectly - due to its reducing effect on $\left[\mathrm{Ca}^{2+}\right]_{i}$ and the subsequent modulation of $\mathrm{I}_{\mathrm{Ca}}$ kinetics - may also prolong it. Consequently, the actual balance of these two counteracting effects may intimately influence the overall result on APD of $\mathrm{I}_{\mathrm{NCX}}$ inhibition, which is hard to predict, and may significantly differ in various arrhythmia models and species. Indeed, this complex relationship may explain the APD reduction by SEA0400, observed following a sotalol/veratridine challenge [43], and - under rather similar experimental conditions - the increased incidence of TdP in Langendorff perfused rabbit hearts following dofetilide treatment [44, 45]. 


\subsection{Global ischaemia}

It is important to mention that the contractility increased in the SEA and the combinated groups compared to the control group. This can be explained by the SEA0400 inhibitory effect on NCX, which results in decreasing the $\mathrm{Ca}^{2+}$ removal from the cytosol, with a consequent increase in $\mathrm{Ca}^{2+}$-transients and higher contractility. These results correspond with our previous work done on isolated rat cardiomyocytes [46] and isolated heart [44] under normoxia, where SEA0400 increased the $\mathrm{Ca}^{2+}$ transient amplitudes. However, since the SEA0400 inhibits both direction of the NCX, this observation can be explained only when Ca removal (forward NCX) is the dominant mode. NHE inhibition blocks the rise of intracellular $\mathrm{Na}^{+}$, and therefore iindirectly prevents the $\mathrm{Ca}^{2+}$ overload through reverse NCX is. When applied in combination with SEA0400, however, the reverse NCX is also inhibired directly by SEA0400. In this situation a synergistic effect could be expected by the combined NHE-NCX inhibition against Ca overload. Our results did not cinfirm this hypothesis, the exact reason for which is unknown. Since SEA0400 equally inhibits the reverse and forward mode NCX, we can speculate that, the attenuated Ca removal due to forward NCX block counteract the beneficial effect of the combined NHE- reverse NCX inhibition.

\subsection{Regional ischaemia}

In the present study, the efficacy of two NCX inhibitors, the fairly selective SEA0400 and the novel, more selective ORM-10103, against reperfusion-induced arrhythmias were analysed in detail. Experimental data on the antiarrhythmic effects of SEA0400 are sparse and contradictory, although mostly positive [47-50], while similar data for ORM-10103 have become available only very recently $[41,51,52]$. SEA0400 has a moderate inhibitory effect on the L-type $\mathrm{Ca}^{2+}$ channels [40], while ORM-10103 has a minor effect on $\mathrm{I}_{\mathrm{Kr}}$; neither of these pleiotropic effects could substantially modulate the observed antiarrhythmic efficacy of the NCX inhibition. Both inhibitors were applied alone or in combination with a well-characterised selective NHE inhibitor, cariporide. Cariporide is proposed to be highly selective and to not influence any of the important ion channels [53-55]. It was assumed that the antiarrhythmic efficacy of a combination of NCX and an NHE inhibitor would be enhanced.

\subsubsection{Rationale}

Lethal ventricular arrhythmias are among the most common reasons of high mortality in patients with acute ischaemia-reperfusion injury. Severe perturbations in intracellular $\mathrm{Na}^{+}$and $\mathrm{Ca}^{2+}$ homeostasis leading to gradually elevated $\left[\mathrm{Na}^{+}\right]_{\mathrm{i}}$ and subsequent $\left[\mathrm{Ca}^{2+}\right]_{\mathrm{i}}$ overload are frequently 
observed in the background of the increased incidence of post-ischaemic ventricular arrhythmias [56]. Recent experimental data demonstrate that these pathological processes are tightly linked to the abnormal activities of two vital sarcolemmal ion transporters, the $\mathrm{Na}^{+} / \mathrm{H}^{+}$exchanger and $\mathrm{Na}^{+} / \mathrm{Ca}^{2+}$ exchanger, key effectors of $\mathrm{pH}_{\mathrm{i}}$ and $\left[\mathrm{Ca}^{2+}\right]_{\mathrm{i}}$ regulation, respectively $[57,58]$. In the majority of related experimental studies, the inhibition of one of these transporters could reduce the incidence and/or severity of ventricular arrhythmias [32, 33, 49, 59, 60]. Therefore, restoring the normal levels of their activities via pharmacological intervention is generally considered a highly feasible therapeutic strategy to prevent, or at least substantially reduce, reperfusioninduced arrhythmogenesis.

NHE inhibition, as a cardioprotective, antiarrhythmic strategy, has also been evaluated in a few clinical trials; however, the routine use of NHE inhibition in human clinical pharmacology is compromised by the fact that, in contrast to the highly promising experimental results, relevant human data obtained from these clinical trials are controversial [34].

Since the data obtained from human trials are not fully satisfactory, in seems reasonable to assume that combining NHE inhibition with other protective interventions may substantially improve its antiarrhythmic efficacy. NCX inhibition is, no doubt, one of the logical choices, however, this approach was never explored in details. Indeed, in contrast to the NHE, NCX - in spite of its obvious significance in pathomechanisms leading to ischaemia/reperfusion induced arrhythmogenesis - is only emerging as a possible target for pharmacological intervention [61]. One reason for this apparent delay may be, that while well established, selective NHE inhibitors have since long been readily available, until recently experimental efforts to evaluate the therapeutic value of NCX inhibition were hampered by the absence of effective, specific inhibitors, therefore often led to unclear results [40]. Another reason for the lack of adequate information on the consequences of pharmacological targeting of NCX in cardiac diseases lies in its complex behavior and poorly understood physiological regulation - while its transport activities into both reverse and forward directions are essential for normal cardiac function, its abnormal activity into any transport direction may initiate and maintain severe cardiac diseases $[58,62]$.

\subsubsection{Experimental model}

For experimental model a widely used arrhythmia protocol with rather short (10 min) regional ischaemia, induced by LAD occlusion, followed by a short (30 min) but complete reperfusion has been selected. An important benefit of this model is that it provides a rapid experimental procedure to study the antiarrhythmic efficacy of a drug in a highly reproducible manner. 
From the aspect of survival and full recovery to normal sinus rhythm the critical arrhythmia type in this model is VF. Without intervention the incidence of VF in control hearts is usually very high, close to 100\% [59], as also has been observed in the present study (Figs. 11 \& 13). Furthermore, though transient (reversible) VF periods could be often observed, in the majority of cases with VF, if initiated, became sustained; it did not terminate spontaneously and the heart was unable to return to normal SR [63]. Further common arrhythmia types, ESs and VT were also often observed in the present experiments.

\subsubsection{NHE inhibition (cariporide alone)}

The antiarrhythmic efficacy of NHE inhibition has been evaluated in a number of studies. Preischaemic administration of cariporide significantly attenuated ischaemia/reperfusion induced arrhythmogenesis in a variety of in vitro and in vivo models [54] while its post-ischaemic administration, though reduced the incidence of VF and subsequent cardiac death, the effect on mortality was not significant $[59,64,65]$. Our results obtained by the pre-ischaemic application of cariporide reflect the high antiarrhythmic efficacy of the treatment, and strongly support the conclusions of similar studies [30-33]. As shown in Figs. 13-15, cariporide significantly increased the duration of the regular sinus rhythm and - with the exception of $\mathrm{ES}_{\mathrm{D}}$ - all arrhythmia-related variables were significantly suppressed by the compound. The high antiarrhythmic efficacy is especially obvious in the case of VT and VF, since both arrhythmia types were almost completely eliminated following its application.

The background for the observed high efficacy of cariporide against VF and VT is not fully clarified. Data from previous studies indicate that during early reperfusion increased NHE activity promotes transient shortening of the APD, which renders the heart susceptible to reentrant arrhythmias, therefore NHE inhibition should significantly reduce the susceptibility of the heart to VF and VT [66]. Furthermore, NHE inhibition has been shown to improve action potential (AP) propagation and reduce the ischaemia-induced increase in AP dispersion, most probably via markedly delaying cell-to-cell electrical uncoupling [67]. Since increased AP dispersion is a critical factor in the initiation and maintenance of VT and VF, improved AP conduction and subsequently decreased dispersion may be an important component in the strong anti-VT and -VF effect of cariporide.

\subsubsection{NCX inhibition (SEA0400 or ORM-10103 alone)}

In the present study, the antiarrhythmic efficacy of SEA0400 was largely subject to the given arrhythmia type. Its application effectively reduced the incidence and duration of triggered arrhythmias (ESs) (Fig. 14), but its efficacy in lengthening the arrhythmia-free SR periods, 
preventing initiation and reducing the duration of VTs and VFs was apparently limited (Figs. 13 \& 15).

Compared to SEA0400, the structure of the novel ORM-10103 is markedly different and its selectivity is enhanced [41]. Regarding its antiarrhythmic effects, when applied alone, ORM10103 resembles SEA0400, but its overall efficacy against triggered arrhythmias (ESs) seems to be even somewhat higher (Fig. 14). Like SEA0400, it moderately increased the length of arrhythmia-free periods (slightly more than SEA0400) (Fig. 12), but unlike SEA0400, it also tended to reduce the incidence and duration of the VFs and VTs (Figs. 13 \& 15). It must be mentioned, however, that although all of these effects could be regularly observed, in most cases, for the large standard deviations, the differences were not significant when using traditional statistical procedures.

The reasons for the strong arrhythmia-type dependence of the efficacy of NCX inhibition against reperfusion-induced arrhythmias are probably complex and may reflect intimate interactions among a few factors with opposite consequences. The excellent protection against triggered arrhythmias may be due to strong inhibition of the reverse NCX transport activity, leading to a significant reduction in reperfusion-induced $\mathrm{Ca}^{2+}{ }_{i}$ load [68-70], while the lack of a similarly beneficial effect of SEA0400 on VFs and VTs suggests that to prevent the induction and maintenance of these arrhythmias, in addition to an effective reduction of the $\mathrm{Ca}^{2+}{ }_{\mathrm{i}}$ overload, a similarly effective suppression of the re-entry activity is also essential [50].

In the present experimental model, VF had by far the largest contribution to total "arrhythmia time"; thus, its influence on the outcome of a pharmacological trial is predominant. Regarding its origin, VF is considered a re-entry type and not triggered-type arrhythmia; the key factor in its induction and maintenance is increased AP dispersion and ischaemia/reperfusion-induced spatial and/or temporal heterogeneities in the resting membrane potential. Consequently, since NCX inhibition is less suitable to protect the heart against substrate-induced arrhythmias, it is not surprising that the efficacy of SEA0400 and ORM-10103 against VF was also limited in our model. Furthermore, since ischaemia is short and incomplete in this arrhythmia model, the elevation of $\left[\mathrm{Ca}^{2+}\right]_{i}$ during ischaemia and upon reperfusion is probably moderate, but heterogeneous. Therefore, activation of the reverse NCX transport mode is probably also moderate but heterogeneous, and the effect of NCX inhibition on the ischaemia/reperfusioninduced $\left[\mathrm{Ca}^{2+}\right]_{\mathrm{i}}$ overload in cardiomyocytes is uneven, unlike how it would be in the case of a severe, long-lasting ischaemia. Nonetheless, both NCX inhibitors substantially reduced the overall incidence of $\mathrm{Ca}^{2+}$-dependent (triggered) arrhythmias, probably originating from locally injured regions. This finding is in line with most of the previous studies reporting the marked efficiency 
of NCX inhibition in reducing the formation of early and delayed after-depolarisations [41, 48]. Indeed, the significantly higher efficiency of NCX inhibition may be expected in conditions where the rise in $\left[\mathrm{Ca}^{2+}\right]_{i}$ is substantially larger and the $\mathrm{Ca}^{2+}$ overload is more pronounced (e.g. following more extensive, complete or long-lasting ischaemia).

\subsubsection{Combined NHE + NCX inhibition}

An unexpected finding of the present study was that cariporide, when applied simultaneously with any of the NCX inhibitors, failed to enhance the antiarrhythmic protection provided by the NCX inhibitor alone. While the effect of SEA+CAR was practically the same as the effect of SEA alone during the SR periods, the simultaneous application of ORM+CAR apparently decreased this parameter (Fig. 12). Qualitatively, the results obtained for both NCX inhibitors and all three arrhythmia types were similar: the simultaneous application of an NHE and an NCX inhibitor did not improve and eventually worsened the moderate antiarrhythmic efficacy of the NCX inhibitor alone.

While the results obtained with single inhibitors are logical and comprehensive, the outcome of the experiments with simultaneous NHE and NCX inhibition first seems highly surprising. Indeed, one would expect that the antiarrhythmic efficacy of simultaneous inhibition should exceed or, at least, meet the efficacy reached alone by any of the contributors. The fact that cariporide alone had significantly higher antiarrhythmic efficacy than in combination with an NCX blocker suggests that NCX inhibition was an important limiting factor in these groups. The reason for this apparent restrain is not clear at present and needs further investigation.

A logical, but largely hypothetical explanation may be as follows. In these experiments, the antiarrhythmic effect of cariporide could not be further improved by a synergic effect of NCX inhibition, since both NHE and reverse NCX inhibition could prevent the $\left[\mathrm{Na}^{+}\right]_{i}$-induced rise in $\left[\mathrm{Ca}^{2+}\right]_{\mathrm{i}}$. Indeed, this assumption is supported by the almost identical effects of combined $\mathrm{NCX}+\mathrm{CAR}$ and NCX alone inhibition. The decreased efficiency of cariporide is most probably caused by inactivation of its beneficial effect on the arrhythmogenic substrate. In other words, in the combined groups, the NCX inhibitors apparently exerted a unique anti-antiarrhythmic effect via releasing the suppressing effect of cariporide treatment and restoring the susceptibility of the heart to re-entrant arrhythmias. This indirect proarrhythmic effect is obviously not present if cariporide is administered alone.

The observed "loss of effect" of cariporide may be related to the significant inhibition of the forward transport mode of NCX by SEA0400 or ORM-10103. Indeed, one may speculate that the beneficial anti-VF effect of cariporide (applied alone) should manifest in decreasing the spatial and/or temporal heterogeneities below the critical level required to evoke fibrillation. 
Simultaneous inhibition of the forward transport mode of NCX may exert an opposite effect by increasing these heterogeneities via inhibiting $\mathrm{Ca}^{2+}$ extrusion needed for restoration of the normal $\mathrm{Ca}^{2+}$ cycle of the cell. This effect may be less important in cardiomyocytes affected by a lower level of ischaemia and subsequent $\left[\mathrm{Ca}^{2+}\right]_{\mathrm{i}}$ load compared to those with more significant rise in $\left[\mathrm{Ca}^{2+}\right]_{i}$. On the other hand, NHE inhibition may remain latent in normal, non-ischaemic myocardium, since NHE is mostly inactive at normal $\mathrm{pH}_{\mathrm{i}}$, while $\mathrm{NCX}$ inhibition undoubtedly affects $\mathrm{Ca}^{2+}$ handling and AP kinetics probably differentially in the ischaemic and non-ischaemic myocardium. Therefore, the consequence of the secondary, forward NCX transport mode inhibition may be a concomitant increase in heterogeneities (eventually shifting those above the critical level), neutralising the beneficial blocking effect of cariporide on VFs. To evaluate the validity of this hypothesis, however, further studies are needed.

\section{CONCLUSION}

Our present data support the hypothesis that selective, partial NCX inhibition may be antiarrhythmic via restricting the $\mathrm{Na}^{+}$-induced $\left[\mathrm{Ca}^{2+}\right]_{i}$ elevation, and this protective effect is mediated primarily by its inhibitory effect on rev $\mathrm{I}_{\mathrm{NCX}}$. Therefore, NCX inhibition can be considered as a promising therapeutic strategy against $\mathrm{Ca}^{2+}$ overload-induced, revNCX-mediated cardiac arrhythmias.

In principle, inhibition of either the NCX or the NHE and especially their combined inhibition should effectively protect the heart against reperfusion-induced harmful arrhythmias, since both mechanisms target and block the same $\left[\mathrm{Ca}^{2+}\right]_{\mathrm{i}}$ overload pathway, at different points. The results of this study, however, are much less straightforward and do not fully support this presumption. The NHE blocker cariporide, if administered alone, by also decreasing the incidence and duration of the re-entrant arrhythmias, provided wider antiarrhythmic efficacy than when applied simultaneously with an NCX inhibitor, in which case the probability of VF induction did not differ significantly from the control. On the other hand, all three inhibitors, alone or in combination, were found to be effective against triggered arrhythmias. Therefore, we concluded that NCX inhibition alone, or in combination with NHE blockade, appears to be a less than optimal therapeutic strategy against the full range of reperfusion-induced arrhythmias. A possible reason for the limited efficacy may be that the currently available selective NCX inhibitors with their equally effective and long-lasting bidirectional blockade of the NCX activity are not fully suitable for this purpose. On the other hand, these NCX inhibitors proved to be highly effective against EAD- and DAD-induced arrhythmias [48]. To better explore the suggested therapeutic potential of combined NCX+NHE inhibition, further studies based on novel NCX inhibitors with different inhibitory characteristics are needed. 


\section{LIMITATIONS}

An important limitation of the present study is that all three inhibitors were used at a single concentration. While it is obvious that a concentration-dependent relationship on the efficacy of a drug or drug combination could be obtained by using several concentrations, applying a single, optimally selected concentration may still satisfactorily characterise its efficacy. In a number of similar studies [71-77], a single drug concentration has been utilised to characterise the effect of an inhibitor on ischaemia-reperfusion injury. In these studies, a concentration-dependent relationship of the inhibitory effect has not been explored. Therefore, we are convinced that our present study will be similarly informative. It should be emphasised, however, that the selection of an optimal concentration is, indeed, critical in order to obtain results that can be considered representative. Therefore, the drug concentrations used here were selected with extreme care especially in the case of NCX inhibitors (e.g. for ORM-10103 $\mathrm{EC}_{50}<0.2 \mu \mathrm{M}$ ).

A second limitation of the present study is that the evaluation of a haemodynamic parameter during the reperfusion phase may be severely hampered or even prevented by the presence of an abnormal heart rhythm (VT or VF), since the correct determination of pressure-related parameters during abnormal heart rhythm periods is practically impossible. Therefore, all haemodynamic values calculated for the reperfusion phase and presented in Table 1 were obtained from hearts devoid of sustained arrhythmias or were evaluated during a period of sinus rhythm between arrhythmic periods. Consequently, one should be aware that while still providing useful information, this analysis may result in substantial bias, as well, and these data should only be considered qualitative.

A third important limitation is that the raw values obtained for the incidence and duration of the ES and VT periods may strongly depend on the length of VF-free periods. In order to provide more realistic information, the summed duration of these periods has been normalised for the summed duration of the VF-free periods. Although these time-normalised values are not completely independent of each other, they still appear to better approximate the duration and incidence of these arrhythmia types in the VF-free heart.

\section{REFERENCES}

1. Manning, A.S. and D.J. Hearse, Reperfusion-induced arrhythmias: mechanisms and prevention. J Mol Cell Cardiol, 1984. 16(6): p. 497-518. 
2. Goldberg, S., et al., Reperfusion arrhythmia: a marker of restoration of antegrade flow during intracoronary thrombolysis for acute myocardial infarction. Am Heart J, 1983. 105(1): p. 26-32.

3. Varro, A. and I. Baczko, Cardiac ventricular repolarization reserve: a principle for understanding drug-related proarrhythmic risk. Br J Pharmacol, 2011. 164(1): p. 14-36.

4. Eisner, D.A., et al., The control of $\mathrm{Ca}$ release from the cardiac sarcoplasmic reticulum: regulation versus autoregulation. Cardiovasc Res, 1998. 38(3): p. 589-604.

5. Murphy, E. and D.A. Eisner, Regulation of intracellular and mitochondrial sodium in health and disease. Circ Res, 2009. 104(3): p. 292-303.

6. Hilleman, D.E. and A.L. Bauman, Role of antiarrhythmic therapy in patients at risk for sudden cardiac death: an evidence-based review. Pharmacotherapy, 2001. 21(5): p. 55675.

7. Fabiato, A., Calcium-induced release of calcium from the cardiac sarcoplasmic reticulum. Am J Physiol, 1983. 245(1): p. C1-14.

8. Dedkova, E.N. and L.A. Blatter, Calcium signaling in cardiac mitochondria. J Mol Cell Cardiol, 2013. 58: p. 125-33.

9. Shannon, T.R., K.S. Ginsburg, and D.M. Bers, Potentiation of fractional sarcoplasmic reticulum calcium release by total and free intra-sarcoplasmic reticulum calcium concentration. Biophys J, 2000. 78(1): p. 334-43.

10. Goldhaber, J.I. and M.A. Hamilton, Role of inotropic agents in the treatment of heart failure. Circulation, 2010. 121(14): p. 1655-60.

11. Goldhaber, J.I. and K.D. Philipson, Cardiac sodium-calcium exchange and efficient excitation-contraction coupling: implications for heart disease. Adv Exp Med Biol, 2013. 961: p. 355-64.

12. Philipson, K.D., S. Longoni, and R. Ward, Purification of the cardiac Na+-Ca2+ exchange protein. Biochim Biophys Acta, 1988. 945(2): p. 298-306. 
13. Nicoll, D.A., S. Longoni, and K.D. Philipson, Molecular cloning and functional expression of the cardiac sarcolemmal $\mathrm{Na}(+)-\mathrm{Ca}+$ exchanger. Science, 1990. 250(4980): p. $562-5$.

14. Cook, O., W. Low, and H. Rahamimoff, Membrane topology of the rat brain Na+Ca2+ exchanger. Biochim Biophys Acta, 1998. 1371(1): p. 40-52.

15. Nicoll, D.A., et al., A new topological model of the cardiac sarcolemmal Na+-Ca2+ exchanger. J Biol Chem, 1999. 274(2): p. 910-7.

16. Li, Z., et al., Identification of a peptide inhibitor of the cardiac sarcolemmal $\mathrm{Na}(+)-$ Ca2+exchanger. J Biol Chem, 1991. 266(2): p. 1014-20.

17. Matsuoka, S., et al., Regulation of the cardiac $\mathrm{Na}(+)-\mathrm{Ca} 2+$ exchanger by $\mathrm{Ca} 2+$. Mutational analysis of the Ca(2+)-binding domain. J Gen Physiol, 1995. 105(3): p. 403-20.

18. Leem, C.H., D. Lagadic-Gossmann, and R.D. Vaughan-Jones, Characterization of intracellular $\mathrm{pH}$ regulation in the guinea-pig ventricular myocyte. J Physiol, 1999. 517 ( $\mathbf{P t}$ 1): p. $159-80$.

19. Cingolani, H.E. and I.L. Ennis, Sodium-hydrogen exchanger, cardiac overload, and myocardial hypertrophy. Circulation, 2007. 115(9): p. 1090-100.

20. Fliegel, L. and M. Karmazyn, The cardiac Na-H exchanger: a key downstream mediator for the cellular hypertrophic effects of paracrine, autocrine and hormonal factors. Biochem Cell Biol, 2004. 82(6): p. 626-35.

21. Ideker, R.E., et al., Ventricular fibrillation and defibrillation--what are the major unresolved issues? Heart Rhythm, 2005. 2(5): p. 555-8.

22. Hausenloy, D.J. and D.M. Yellon, Myocardial ischemia-reperfusion injury: $a$ neglected therapeutic target. J Clin Invest, 2013. 123(1): p. 92-100.

23. Blaustein, M.P., M. Juhaszova, and V.A. Golovina, The cellular mechanism of action of cardiotonic steroids: a new hypothesis. Clin Exp Hypertens, 1998. 20(5-6): p. 691-703.

24. Goldhaber, J.I., Sodium-calcium exchange: the phantom menace. Circ Res, 1999. 85(11): p. 982-4. 
25. Dipla, K., et al., The sarcoplasmic reticulum and the $\mathrm{Na}+\mathrm{Ca}+$ exchanger both contribute to the Ca2+ transient of failing human ventricular myocytes. Circ Res, 1999. 84(4): p. 435-44.

26. Tanaka, H., et al., Effect of SEA0400, a novel inhibitor of sodium-calcium exchanger, on myocardial ionic currents. Br J Pharmacol, 2002. 135(5): p. 1096-100.

27. Magee, W.P., et al., Differing cardioprotective efficacy of the $\mathrm{Na}+\mathrm{Ca} 2+$ exchanger inhibitors SEA0400 and KB-R7943. Am J Physiol Heart Circ Physiol, 2003. 284(3): p. H90310.

28. Khananshvili, D., et al., Positively charged cyclic hexapeptides, novel blockers for the cardiac sarcolemma Na(+)-Ca2+exchanger. J Biol Chem, 1995. 270(27): p. 16182-8.

29. Iwamoto, T., et al., The exchanger inhibitory peptide region-dependent inhibition of $\mathrm{Na}+/ \mathrm{Ca} 2+$ exchange by SN-6 [2-[4-(4-nitrobenzyloxy)benzyl]thiazolidine-4-carboxylic acid ethyl ester], a novel benzyloxyphenyl derivative. Mol Pharmacol, 2004. 66(1): p. 45-55.

30. Scholz, W. and U. Albus, Na+/H+ exchange and its inhibition in cardiac ischemia and reperfusion. Basic Res Cardiol, 1993. 88(5): p. 443-55.

31. Sack, S., et al., Effects of a new $\mathrm{Na}+/ \mathrm{H}+$ antiporter inhibitor on postischemic reperfusion in pig heart. J Cardiovasc Pharmacol, 1994. 23(1): p. 72-8.

32. Xue, Y.X., N.N. Aye, and K. Hashimoto, Antiarrhythmic effects of HOE642, a novel $\mathrm{Na}(+)-\mathrm{H}+$ exchange inhibitor, on ventricular arrhythmias in animal hearts. Eur J Pharmacol, 1996. 317(2-3): p. 309-16.

33. Yasutake, M., et al., $\mathrm{Na}+/ \mathrm{H}+$ exchange and reperfusion arrhythmias: protection by intracoronary infusion of a novel inhibitor. Am J Physiol, 1994. 267(6 Pt 2): p. H2430-40.

34. Mentzer, R.M., Jr., et al., Intracellular sodium hydrogen exchange inhibition and clinical myocardial protection. Ann Thorac Surg, 2003. 75(2): p. S700-8.

35. Toth, A., et al., Potential therapeutic effects of $\mathrm{Na}+/ \mathrm{Ca} 2+$ exchanger inhibition in cardiac diseases. Curr Med Chem, 2009. 16(25): p. 3294-321. 
36. Antoons, G., R. Willems, and K.R. Sipido, Alternative strategies in arrhythmia therapy: evaluation of $\mathrm{Na} / \mathrm{Ca}$ exchange as an anti-arrhythmic target. Pharmacol Ther. 134(1): p. 26-42.

37. Roberts, B.N. and D.J. Christini, NHE inhibition does not improve $\mathrm{Na}(+)$ or $\mathrm{Ca}(2+)$ overload during reperfusion: using modeling to illuminate the mechanisms underlying a therapeutic failure. PLoS Comput Biol, 2011. 7(10): p. e1002241.

38. Nagy, N., et al., Does small-conductance calcium-activated potassium channel contribute to cardiac repolarization? J Mol Cell Cardiol, 2009. 47(5): p. 656-63.

39. Masereel, B., L. Pochet, and D. Laeckmann, An overview of inhibitors of $\mathrm{Na}(+) / \mathrm{H}(+)$ exchanger. Eur J Med Chem, 2003. 38(6): p. 547-54.

40. Birinyi, P., et al., Effects of SEAO400 and KB-R7943 on Na+/Ca2+ exchange current and L-type Ca2 + current in canine ventricular cardiomyocytes. Naunyn Schmiedebergs Arch Pharmacol, 2005. 372(1): p. 63-70.

41. Jost, N., et al., ORM-10103, a novel specific inhibitor of the $\mathrm{Na}+\mathrm{Ca} 2+$ exchanger, decreases early and delayed afterdepolarizations in the canine heart. Br J Pharmacol, 2013. 170(4): p. 768-78.

42. Imura, H., B.E. Ayres, and M.S. Suleiman, Purine metabolism and release during cardioprotection with hyperkalemia and hypothermia. Mol Cell Biochem, 2002. 237(1-2): p. 119-27.

43. Milberg, P., et al., Inhibition of the $\mathrm{Na}+\mathrm{Ca} 2+$ exchanger suppresses torsades de pointes in an intact heart model of long QT syndrome-2 and long QT syndrome-3. Heart Rhythm, 2008. 5(10): p. 1444-52.

44. Farkas, A.S., et al., $\mathrm{Na}(+) / \mathrm{Ca}(2+)$ exchanger inhibition exerts a positive inotropic effect in the rat heart, but fails to influence the contractility of the rabbit heart. $\mathrm{Br} \mathrm{J}$ Pharmacol, 2008. 154(1): p. 93-104.

45. Farkas, A.S., et al., The role of the $\mathrm{Na}+\mathrm{Ca}+$ exchanger, $\mathrm{I}(\mathrm{Na})$ and $\mathrm{I}(\mathrm{CaL})$ in the genesis of dofetilide-induced torsades de pointes in isolated, AV-blocked rabbit hearts. $\mathrm{Br} \mathrm{J}$ Pharmacol, 2009. 156(6): p. 920-32. 
46. Acsai, K., et al., Effect of partial blockade of the $\mathrm{Na}(+) / \mathrm{Ca}(2+)$-exchanger on $\mathrm{Ca}(2+)$ handling in isolated rat ventricular myocytes. Eur J Pharmacol, 2007. 576(1-3): p. 1-6.

47. Amran, M.S., K. Hashimoto, and N. Homma, Effects of sodium-calcium exchange inhibitors, KB-R7943 and SEA0400, on aconitine-induced arrhythmias in guinea pigs in vivo, in vitro, and in computer simulation studies. J Pharmacol Exp Ther, 2004. 310(1): p. 83-9.

48. Nagy, Z.A., et al., Selective inhibition of sodium-calcium exchanger by SEA-0400 decreases early and delayed after depolarization in canine heart. Br J Pharmacol, 2004. 143(7): p. 827-31.

49. Nagasawa, Y., et al., Effects of SEA0400, a Na+/Ca2+ exchange inhibitor, on ventricular arrhythmias in the in vivo dogs. Eur J Pharmacol, 2005. 506(3): p. 249-55.

50. Chou, C.C., et al., Effects of SEA0400 on arrhythmogenicity in a Langendorff-perfused 1-month myocardial infarction rabbit model. Pacing Clin Electrophysiol. 36(5): p. 596-606.

51. Kormos, A., et al., Efficacy of selective NCX inhibition by ORM-10103 during simulated ischemia/reperfusion. Eur J Pharmacol, 2014. 740: p. 539-51.

52. Nagy, N., et al., Selective Na /Ca exchanger inhibition prevents Ca overload induced triggered arrhythmias. Br J Pharmacol, 2014.

53. Madonna, R. and R. De Caterina, Sodium-hydrogen exchangers (NHE) in human cardiovascular diseases: interfering strategies and their therapeutic applications. Vascul Pharmacol, 2013. 59(5-6): p. 127-30.

54. Scholz, W., et al., Protective effects of HOE642, a selective sodium-hydrogen exchange subtype 1 inhibitor, on cardiac ischaemia and reperfusion. Cardiovasc Res, 1995. 29(2): p. 260-8.

55. Bebarova, M., et al., Dual effect of ethanol on inward rectifier potassium current IK1 in rat ventricular myocytes. J Physiol Pharmacol, 2014. 65(4): p. 497-509.

56. Ter Keurs, H.E. and P.A. Boyden, Calcium and arrhythmogenesis. Physiol Rev, 2007. 87(2): p. 457-506. 
57. Karmazyn, M., et al., The myocardial $\mathrm{Na}(+)-H(+)$ exchange: structure, regulation, and its role in heart disease. Circ Res, 1999. 85(9): p. 777-86.

58. Khananshvili, D., The SLC8 gene family of sodium-calcium exchangers (NCX) structure, function, and regulation in health and disease. Mol Aspects Med, 2013. 34(2-3): p. 220-35.

59. Aye, N.N., Y.X. Xue, and K. Hashimoto, Antiarrhythmic effects of cariporide, a novel $\mathrm{Na}+\mathrm{H}+$ exchange inhibitor, on reperfusion ventricular arrhythmias in rat hearts. Eur $\mathrm{J}$ Pharmacol, 1997. 339(2-3): p. 121-7.

60. Szentandrassy, N., et al., Tetrodotoxin blocks native cardiac L-type calcium channels but not CaV1.2 channels expressed in HEK cells. J Physiol Pharmacol, 2013. 64(6): p. 80710.

61. Iwamoto, T., Forefront of $\mathrm{Na}+/ \mathrm{Ca}+$ exchanger studies: molecular pharmacology of Na+/Ca2+ exchange inhibitors. J Pharmacol Sci, 2004. 96(1): p. 27-32.

62. Lehnart, S.E., L.S. Maier, and G. Hasenfuss, Abnormalities of calcium metabolism and myocardial contractility depression in the failing heart. Heart Fail Rev, 2009. 14(4): p. 21324.

63. Avkiran, M. and C. Ibuki, Reperfusion-induced arrhythmias. A role for washout of extracellular protons? Circ Res, 1992. 71(6): p. 1429-40.

64. Takahashi, K., et al., Protective effects of SEA0400, a novel and selective inhibitor of the Na+/Ca2+ exchanger, on myocardial ischemia-reperfusion injuries. Eur J Pharmacol, 2003. 458(1-2): p. 155-62.

65. Zhang, Y., et al., Cariporide attenuates myocardial ischaemia, reperfusion injury and apoptosis in isolated rat hearts. Acta Cardiol, 2006. 61(6): p. 637-41.

66. Wirth, K.J., T. Maier, and A.E. Busch, NHE1-inhibitor cariporide prevents the transient reperfusion-induced shortening of the monophasic action potential after coronary ischemia in pigs. Basic Res Cardiol, 2001. 96(2): p. 192-7. 
67. Rodriguez-Sinovas, A., et al., Pre-treatment with the $\mathrm{Na}+/ \mathrm{H}+$ exchange inhibitor cariporide delays cell-to-cell electrical uncoupling during myocardial ischemia. Cardiovasc Res, 2003. 58(1): p. 109-17.

68. Seki, S., et al., Inhibition by $\mathrm{KB}-\mathrm{r} 7943$ of the reverse mode of the $\mathrm{Na} / \mathrm{Ca}+$ exchanger reduces Ca2+ overload in ischemic-reperfused rat hearts. Circ J, 2002. 66(4): p. $390-6$.

69. Wang, J., et al., SEA0400, a novel $\mathrm{Na}+\mathrm{Ca}+$ exchanger inhibitor, reduces calcium overload induced by ischemia and reperfusion in mouse ventricular myocytes. Physiol Res, 2007. 56(1): p. 17-23.

70. Hobai, I.A. and B. O'Rourke, The potential of $\mathrm{Na}+\mathrm{Ca}+$ exchange blockers in the treatment of cardiac disease. Expert Opin Investig Drugs, 2004. 13(6): p. 653-64.

71. Matsumoto, T., et al., Blockade of the $\mathrm{Na}+-\mathrm{Ca} 2+$ exchanger is more efficient than blockade of the Na+-H+ exchanger for protection of the myocardium from lethal reperfusion injury. Cardiovasc Drugs Ther, 2002. 16(4): p. 295-301.

72. Hartmann, M. and U.K. Decking, Blocking $\mathrm{Na}(+)-\mathrm{H}+$ exchange by cariporide reduces $\mathrm{Na}(+)$-overload in ischemia and is cardioprotective. J Mol Cell Cardiol, 1999. 31(11): p. 1985-95.

73. Milberg, P., et al., Acute inhibition of the $\mathrm{Na}(+) / \mathrm{Ca}(2+)$ exchanger reduces proarrhythmia in an experimental model of chronic heart failure. Heart Rhythm, 2012. 9(4): p. $570-8$.

74. Alexandrou, A.J., et al., The human ether-a'-go-go related gene (hERG) K+ channel blockade by the investigative selective-serotonin reuptake inhibitor CONA-437: limited dependence on S6 aromatic residues. J Physiol Pharmacol, 2014. 65(4): p. 511-23.

75. Namekata, I., et al., Reduction by SEA0400 of myocardial ischemia-induced cytoplasmic and mitochondrial Ca2+ overload. Eur J Pharmacol, 2006. 543(1-3): p. 108-15.

76. Namekata, I., et al., Cardioprotection without cardiosuppression by SEA0400, a novel inhibitor of $\mathrm{Na}+\mathrm{Ca} 2+$ exchanger, during ischemia and reperfusion in guinea-pig myocardium. Life Sci, 2005. 77(3): p. 312-24. 
77. Dhein, S., et al., Effects of the type-1 Na+/H+-exchange inhibitor cariporide (Hoe 642) on cardiac tissue. Naunyn Schmiedebergs Arch Pharmacol, 1998. 357(6): p. 662-70. 


\section{ANNEX}

Publications related to the subject of the Thesis. 


\section{ACKNOLEDGEMENTS}

I am very grateful to Professor András Varró, MD, DSc, for his continuous support and for providing me the opportunity for research at the Department of Pharmacology and Pharmacotherapy and to Professor Gyula Papp MD, DSc, academician for his criticism and helpful advice.

I am especially thankful to my supervisors András Tóth, $\mathrm{PhD}$, for his continuous support and personal guidance at the Department of Pharmacology and Pharmacotherapy and for introducing me to the fluorescent techniques. His personal guidance and helpful discussions were useful during my work and allowed me to learn the critical thinking in the scientific field

I wish to thank my grateful colleague, Károly Acsai $\mathrm{PhD}$, for his continuous support and help to study the experimental techniques in the field of the electrophysiology.

I would like to thank all my direct colleagues, Norbert Nagy PhD; János Prorok PhD, Anita Kormos PhD; Andrea Gruber for their help in my work. I am also very thankful to Zsuzsanna Sebők for her helpful technical assistance.

A particular acknowledgement goes to my parents, brother, sister, and all my friends for their help and encouragement, to whom I dedicated this $\mathrm{PhD}$ thesis. Finally, my deepest appreciation goes to my love, Sándor, for his love, support and encouragement in the past years.

The publication is supported by the Richter Gedeon Centenáriumi Foundation. 